\title{
Philosophical Approaches to Compositional Technique in Isang Yun's Works for Solo Flute
}

\author{
Mirim Lee
}

Follow this and additional works at: https://researchrepository.wvu.edu/etd

\section{Recommended Citation}

Lee, Mirim, "Philosophical Approaches to Compositional Technique in Isang Yun's Works for Solo Flute" (2017). Graduate Theses, Dissertations, and Problem Reports. 6052.

https://researchrepository.wvu.edu/etd/6052

This Dissertation is protected by copyright and/or related rights. It has been brought to you by the The Research Repository @ WVU with permission from the rights-holder(s). You are free to use this Dissertation in any way that is permitted by the copyright and related rights legislation that applies to your use. For other uses you must obtain permission from the rights-holder(s) directly, unless additional rights are indicated by a Creative Commons license in the record and/ or on the work itself. This Dissertation has been accepted for inclusion in WVU Graduate Theses, Dissertations, and Problem Reports collection by an authorized administrator of The Research Repository @ WVU.

For more information, please contact researchrepository@mail.wvu.edu. 


\title{
Philosophical Approaches to Compositional Technique
} in Isang Yun's Works for Solo Flute

\section{Mirim Lee}

\author{
Dissertation Submitted \\ to the College of Creative Arts \\ at West Virginia University \\ in partial fulfillment of the requirements for the degree of \\ Doctor of Musical Arts \\ in \\ Flute Performance
}

\begin{abstract}
Michael Ibrahim, D.M.A., Committee Chair
Nina Assimakopoulos, M.M.

Keith Jackson, D.M.A.

Evan MacCarthy, Ph.D, Research Advisor

General Hambrick, M.F.A.
\end{abstract}

\author{
School of Music \\ Morgantown, West Virginia \\ 2017
}

Keywords: Flute, Contemporary, Isang Yun, Korean Music, Korean Traditional Music, Philosophy, Composition, Taoism, Yin and Yang, Main Tone Sound, Sigimsae

Copyright 2017 Mirim Lee 


\section{ABSTRACT \\ Philosophical Approaches to Compositional Technique \\ in Isang Yun's Works for Solo Flute}

Mirim Lee

As modern composers draw on an ever-widening source of inspiration from musical traditions and practices around the world, the music of twentieth-century Korean composers deserves greater recognition and increased performance within Western culture. This is especially true of the works of Korean-German composer Isang Yun (1917-1995), a prolific composer whose output is largely unknown in Korea. This research paper will examine selected works for solo flute by Yun with particular attention to Sori (1988).

Isang Yun studied composition under Tony Aubin (1907-1981) and Pierre Revel (19011984) at the Paris Conservatory from 1956-1957. He also studied in West Berlin at the Musikhochschule Berlin (today the Berlin University of Arts) under Boris Blacher (1903-1975), Josef Rufer (1893-1985), and Reinhard Schwarz-Schilling (1904-1985). In 1958, Yun participated in the International Summer Courses of Contemporary Music in Darmstadt, and began his European career with premieres of Music for Seven Instruments (1959) in 1961 and Reak (1966), both of which brought him international recognition.

Yun's works reflect his interest in Eastern philosophy, as studied early in his career and combined with the avant-garde style he developed during his years teaching and studying in Germany. The influences of Taoism, Yin and Yang, Stillness in Motion, and Humanism are prevalent throughout his compositional output. Yun works with these ideas in novel ways and also applies them techniques of other composers, including Haupttontechnik (main tone technique), Hauptklangtechnik (main-sound technique), Tonkomplex (tone complex), Klangfarbenkomposition (sound-color composition), and Umspielung (replay, playing around, or rounding), to create his own unique compositional style. This paper explores in detail his use of these Eastern philosophical concepts as applied to works for solo flute, specifically Sori. 


\section{DEDICATION}

This paper is dedicated to my grandmother who is now in Heaven. I am sorry I was not able to stay with you for your last moments and I will always be grateful for your endless love. I love you so much, Grandmother. 


\section{ACKNOWLEDGEMENT}

I am very grateful to West Virginia University and to the faculty members in the School of Music, who have guided and supported me throughout the writing of this research paper. I would particularly like to thank Dr. Evan MacCarthy, who has spent many hours and given of his time and energy freely in helping me shape this research topic. I have sincerely appreciated his kindness and dedication. I would also like to thank Professor Nina Assimakopoulos, who has been instrumental in aiding my growth and development as a flutist and an artist. Her support throughout the completion of my degrees has been invaluable.

I would like to acknowledge the other members of my DMA committee as well: Dr. Michael Ibrahim, Dr. Keith Jackson, and Professor General Hambrick, all of whom have contributed to this project significantly. The wisdom and support of my committee helped this research project become a reality and I could not have completed this without the help of each member.

I would also like to thank my dear friends: Alyssa Schwartz, Eftihia Victoria Arkoudis, and Tatiana Cassetta for being true friends and encouraging me throughout the completion of my degrees. Additionally, I am grateful for the advice of Angela Collier Reynolds and Angel Lin, both of whom have provided sound advice and feedback on the construction of this research paper.

Finally, I would like to thank my parents and my wonderful husband, Jun-Hyung Baek, who have believed in me and encouraged me to achieve my goals. Without the faith and support of my beloved family, I would not be where I am today.

All your loving care has given me the strength needed to complete my education throughout this long, exciting, and difficult journey. Thank you, and love to you all. 


\section{TABLE OF CONTENTS}

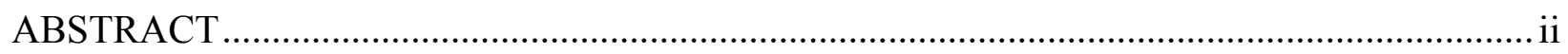

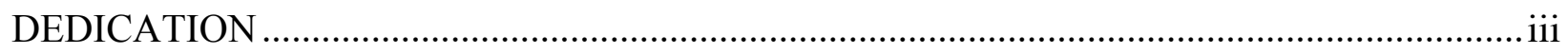

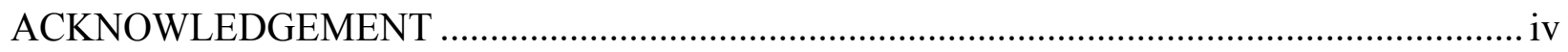

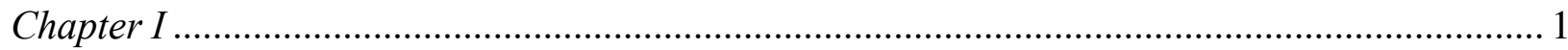

Introduction/ Review of Literature ........................................................................................ 1

Introduction

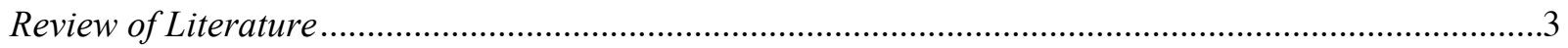

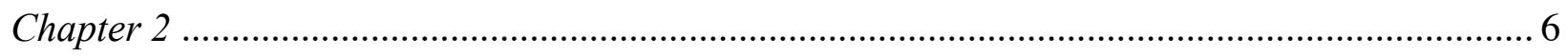

Life and Musical Background of Isang Yun, and Lists of His Flute Works .................................. 6

Life and Musical Background of Isang Yun ................................................................................6

Lists of Isang Yun's Flute Works ...............................................................................................13

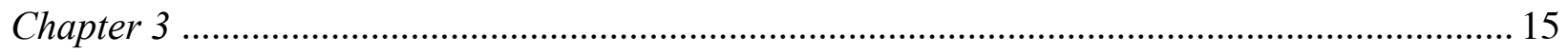

Eastern Philosophy and Compositional Techniques in Yun's Music ......................................... 15

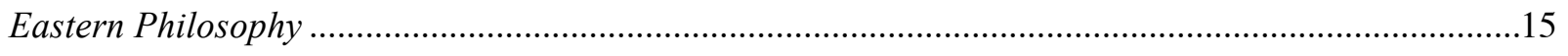

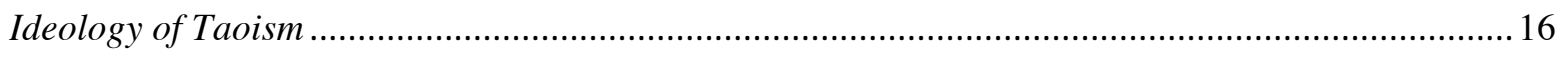

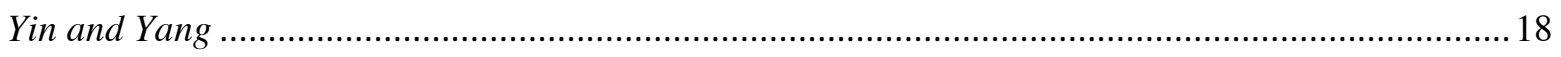

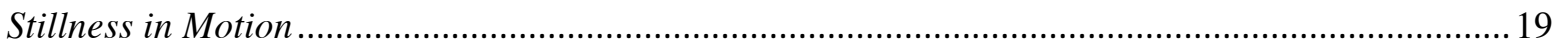

The Spirit of Humanism …………………………………………………………………. 20

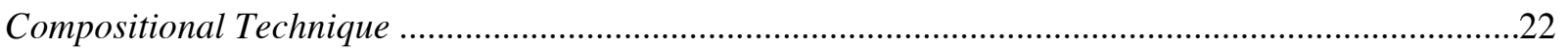

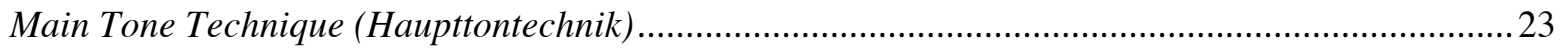

Main Sound Technique (Hauptklangtechnik) .............................................................................2 24 


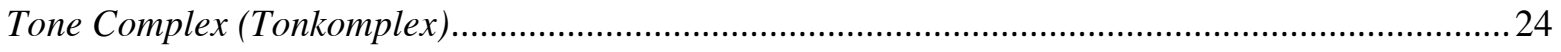

Sound Color Composition (Klangfarbenkomposition) ….........................................................25

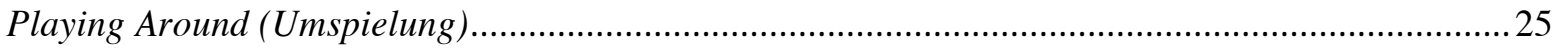

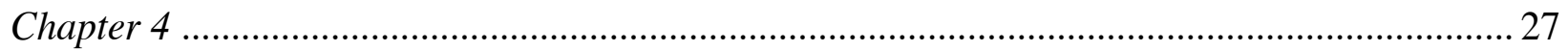

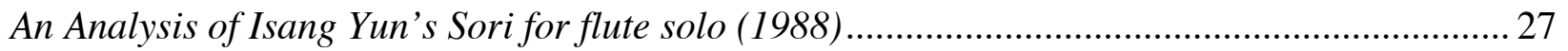

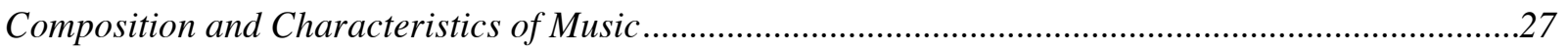

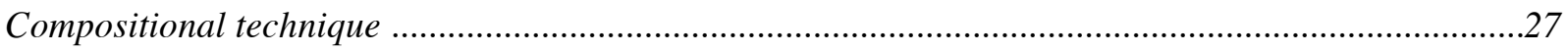

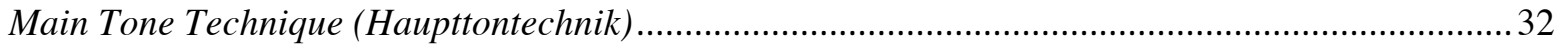

Main Sound Technique (Hauptklangtechnik) …........................................................................ 37

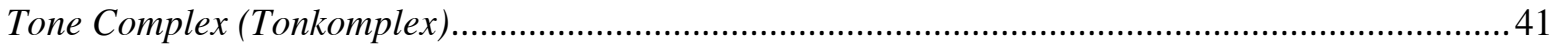

Sound Color Composition (Klangfarbenkomposition) ….............................................................. 42

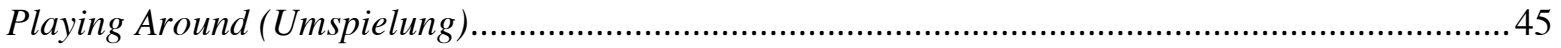

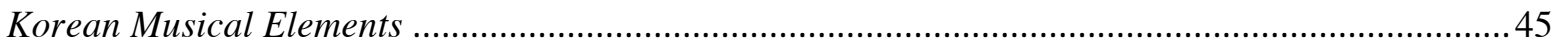

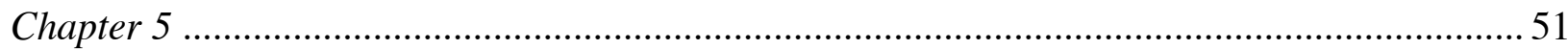

Analyses of Other Works for Solo Flute and Selected Chamber Works by Isang Yun ............... 51

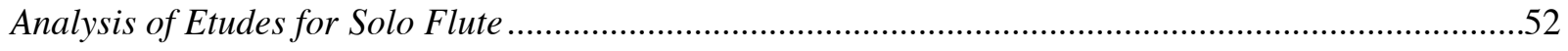

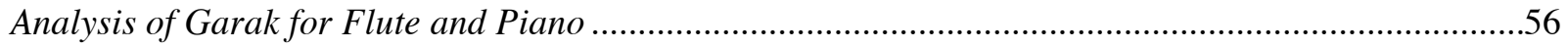

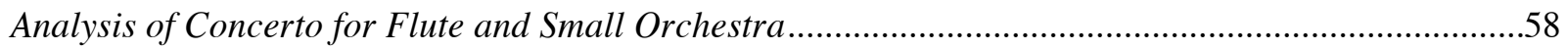

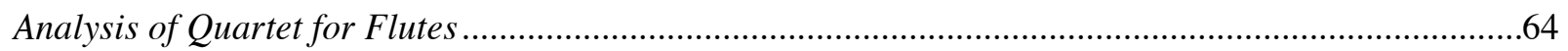

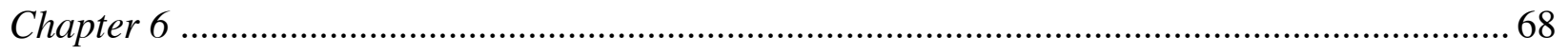

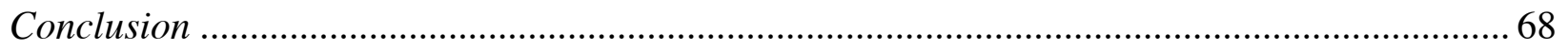

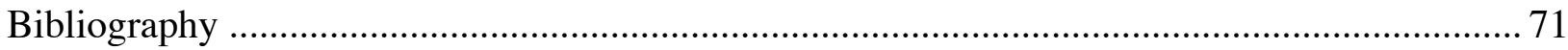




\section{TABLE OF EXAMPLES}

Example

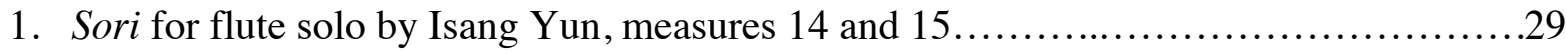

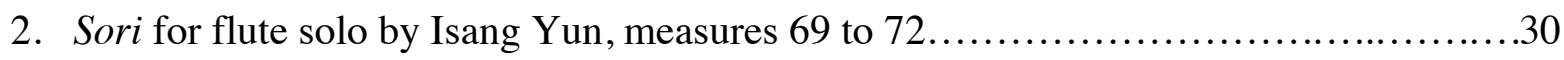

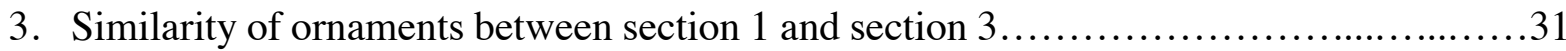

4. Sori for flute solo by Isang Yun, Similarities between section 1 and section 3...........32

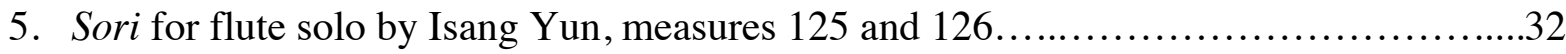

6. From the book 'My way, My Ideal, My Music'

By Isang Yun and Walter-Wolfgang Sparrer, Hice, 1994, p. 112................33

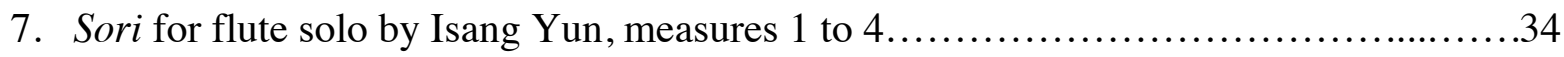

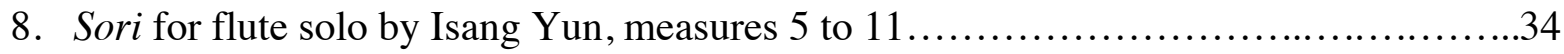

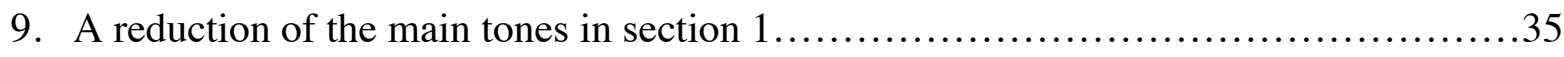

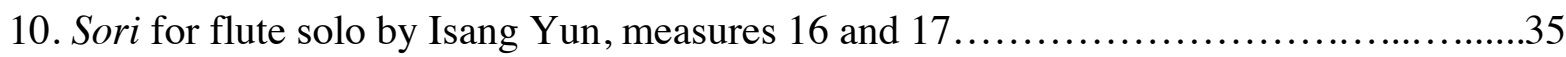

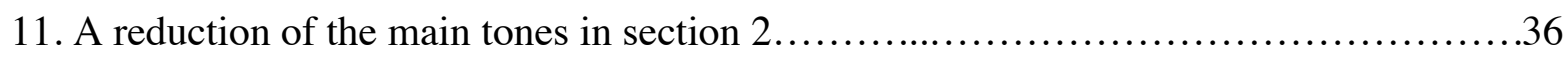

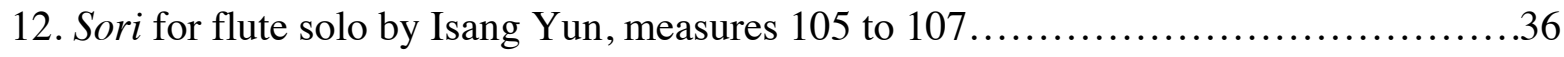

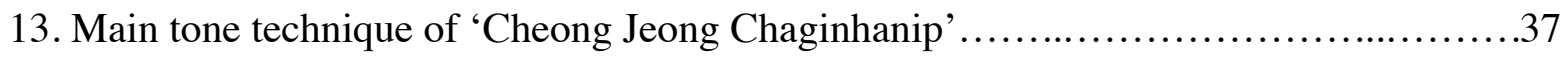

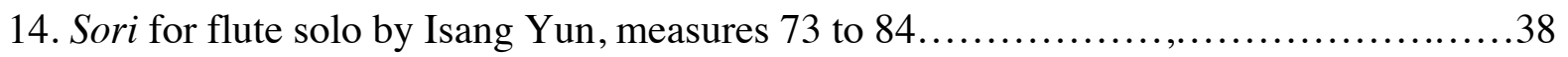

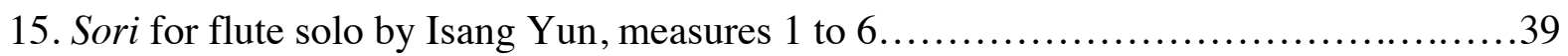

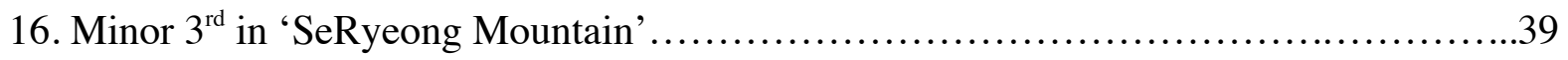

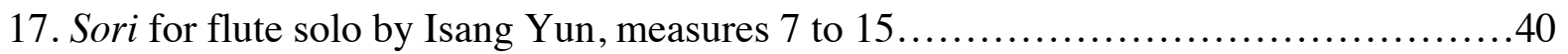

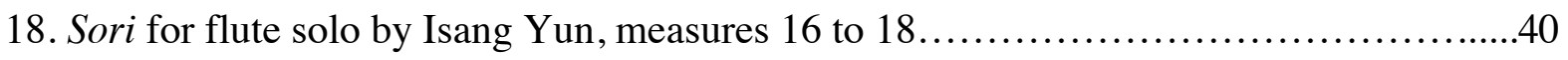

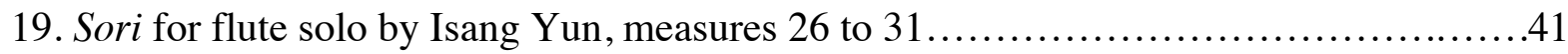

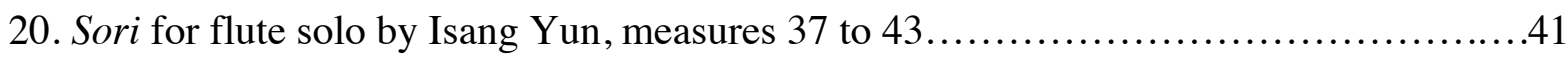

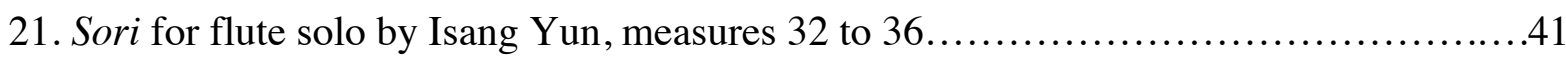

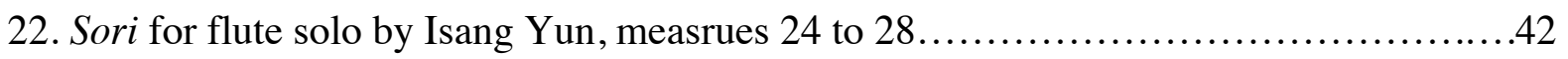

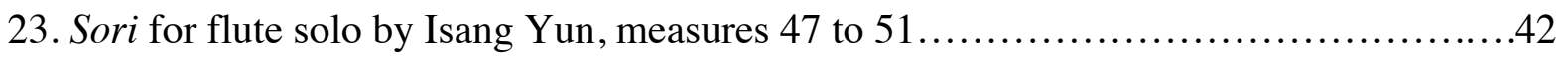

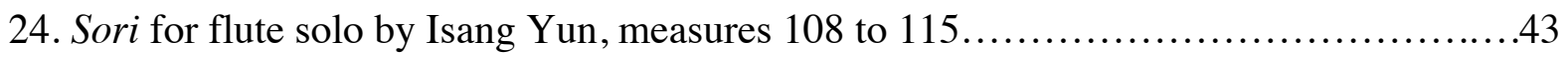

25. Grace notes and trills as ornamentation in "Jinyanjo".............................45

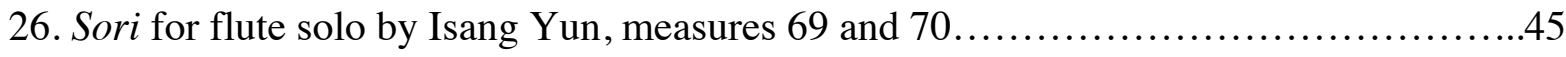

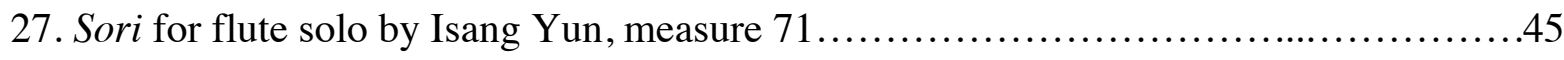

28. Example of 'Cheong Jeong Chaginhanip' .......................................45

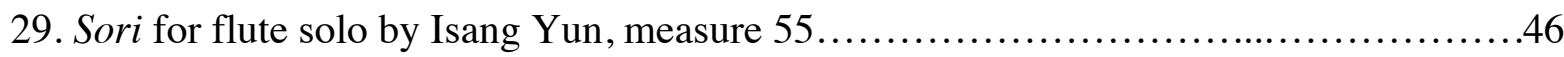

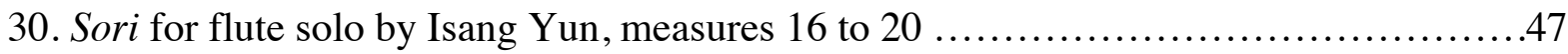

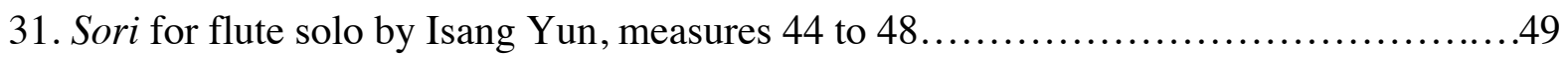

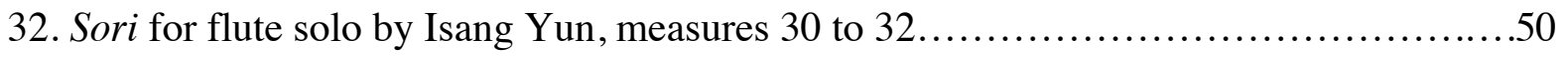

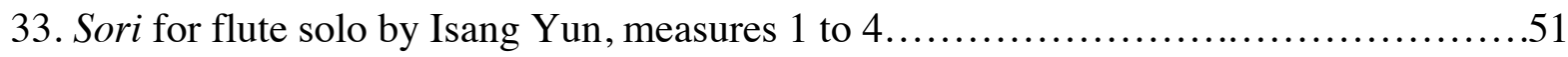

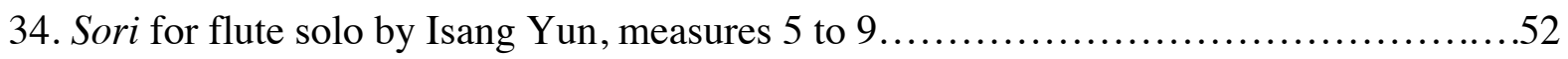




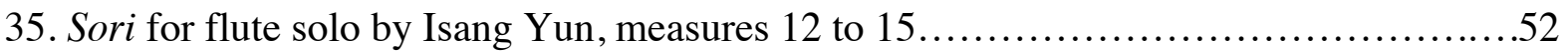

36. Etude for flute solo by Isang Yun, 1 . Moderato, measures 1 to $4 \ldots \ldots \ldots \ldots \ldots \ldots \ldots \ldots . \ldots 5$

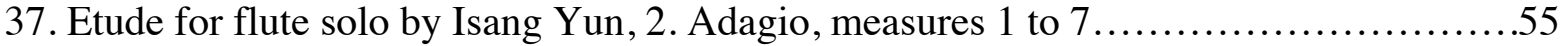

38. Etude for flute solo by Isang Yun, 3. Allegro, measures 1 and $2 \ldots \ldots \ldots \ldots \ldots \ldots \ldots \ldots \ldots$

39. Etude for flute solo by Isang Yun, 4. Andante, measures 1 to $4 \ldots \ldots \ldots \ldots \ldots \ldots \ldots \ldots \ldots . .57$

40. Etude for flute solo by Isang Yun, 5, Allegretto, measures 1 to $4 \ldots \ldots \ldots \ldots \ldots \ldots \ldots \ldots . \ldots . \ldots \ldots$

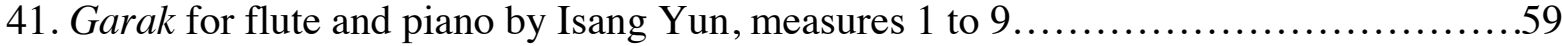

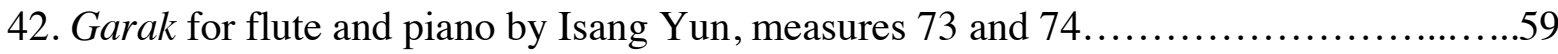

43. Garak for flute and piano by Isang Yun, measures 122 and 123, measures 167 and 168.59

44. Flute Concerto and Small Orchestra by Isang Yun, measures 1 to $4 \ldots \ldots \ldots \ldots \ldots \ldots \ldots . . . . . .63$

45. Flute Concerto and Small Orchestra by Isang Yun, measures 104 to $108 \ldots \ldots \ldots \ldots \ldots \ldots . . .63$

46. Flute Concerto and Small Orchestra by Isang Yun, measures 172 to 175, Cadenza.......63

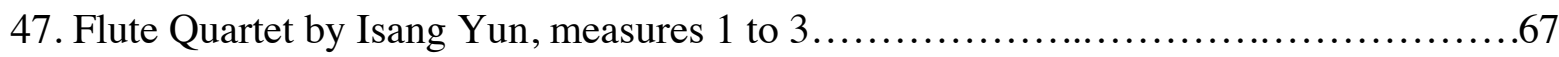

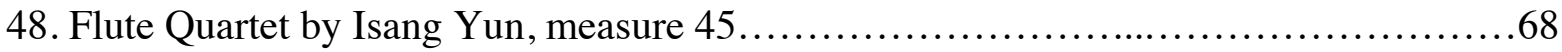

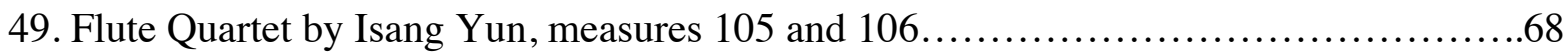

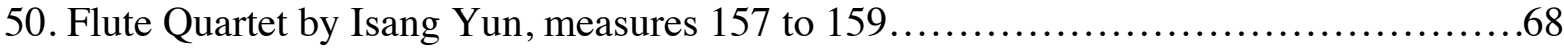




\section{Chapter I}

\section{Introduction/ Review of Literature}

\section{Introduction}

Isang Yun (1917-1995) is a noteworthy, twentieth-century Korean composer whose career, musical aesthetic, and compositional output is substantial and well-known, and therefore more comparable to those of Western composers than many of his Korean contemporaries. Though Yun's compositional style is grounded in principles of Western contemporary music, his work also displays influences from East Asian musical traditions. These pluralistic influences were key in facilitating Yun's interaction with avant-garde composers in the middle of the twentieth century.

Yun's writing tends to favor utilizing Western instrumentation and East Asian melodic ideas and motives, which promoted the performance of his works throughout the West during his lifetime. Although Yun employed a number of traditional compositional techniques that are native, and familiar, to Korean music, his works remain largely unknown to twenty-first century Korean composers for two significant reasons. The first reason is political: the South Korean government claimed that Yun had communicated with a North Korean friend. This accusation resulted in few performances of Yun's music in Korea and minimal scholarly research on his works. The seriousness of this claim even resulted in the halting of a performance of one of his 
works. ${ }^{12}$ The second reason is cultural: where in earlier times the Western world has had an extremely strong influence on world culture, Eastern culture is beginning to gain traction and attention in the modern world today, perhaps due to the continued and indiscriminate absorption of different social customs. In the socio-culturally astute twenty-first century, creativity and collaboration are more important than ever, and this research paper aims to help promote Isang Yun and his works throughout Korea.

This paper will explore how East Asian philosophy, found at the root of many of Yun's musical compositions, is expressed in his works for flute-- specifically, his solo flute work Sori. It will examine the life and works of Isang Yun, discuss the East Asian philosophical movements that influenced his musical aesthetic, and analyze the compositional techniques that he employed to capture their different facets. This research revolves around a close analysis of Sori's compositional design, as well as those of other selected chamber works for flute. Isang Yun claimed that "the flute instrument was a suitable Western instrument that added light to my music". ${ }^{3}$ Furthermore, this paper will analyze how Sori and Yun's other works involving the sound of the Korean flute are connected to the Western flute. Finally, this paper will conclude with a discussion of performance practice, highlighting how these East Asian elements are expressed in notation and in performance.

\footnotetext{
${ }^{1}$ The East Berlin Affiar took place between 1967 and 1970.

${ }^{2}$ Young Sun Seo "A Study on Traditional Composition Techniques of 'Sori for Flute Solo,' (1988) by Isang Yun," (MM thesis, ChangWon University, 2013), 1-2.

${ }^{3}$ Eunmi Hong, "Isang Yun, his life and his music," Monthly Keum-ho Magazine Vol. 14 (December 1995), 24.
} 


\section{Review of Literature}

Previously published scholarship on this topic can be found in various articles, books, graduate theses, and dissertations, as well as magazines and Korean blogs. Yun's musical background began with a Korean period in his childhood home of Tongyeong which was followed by a shift to a distinctly European feel. Notable research on Yun and his musical training and development has been produced by such as scholars as Dea Wook Kim (2013), Laura Hauser (2009), Dae-Sik Hur (2005), Eun Jung Jung (2017), Jin Kyung Moon (2017), Ju Hee Kim (2009), Jeong Seok Lee (2011), Song Young Kim (2011), and Yun Jeong Kim (2013). ${ }^{4}$ Their writings reveal that his initial period of musical development was influenced heavily by Korean folk music, which he heard growing up from his mother and neighbors. Yun also studied in Japan, however, which exposed him to other forms of traditional East Asian music. He would later continue his studies in Paris and Germany, where his music found a wider audience. It was then that Yun began to develop his own signature compositional techniques and engage artistically with East Asian philosophical concepts as Eunmi Hong (1995), and Yong Whan Kim (2001). ${ }^{5}$

\footnotetext{
${ }^{4}$ Dea Wook Kim, "The Integration of Western Technique with East Asian Philosophies in Isang Yun's Quartett Für Horn, Trompete, Posaune Und Klavier"(DMA diss., University of North Texas, 2013); Laura Hauser, "A Performer's Analysis of Isang Yun's Monolog for Bassoon with an Emphasis on the Role of Traditional Korean Influences." (DMA diss., Louisiana State University, 2009); Dae-Sik Hur, "A Combination of Asian Language with Foundations of Western Music" (DMA diss., University of North Texas, 2005); Eun Jung Jung, “A Full Realization of Isang Yun's "Tuyaux Sonores" and Its Analysis Based on Daoism" (DMA diss., California State University Long Beach,2017); Jin Kyung Moon, "Study of Isang Yun's Exemplum in Memoriam Kwangju" (DMA diss., University of Georgia, 2017); Ju Hee Kim, "Multicultural Influcnes in the Music of Isang Yun as Represented in His Concerto for Flute and Small Orchestra" (DMA diss., University of Alabama, 2009); Jeong Seok Lee, "The Interaction of Korean and Western Practices in Isang Yun's Piri for Oboe Solo and Other Works" (DMA diss., California State University Long Beach, 2011); Song Young Kim, "The Concept of "Unity" In Isang Yun's Konigliches Thema fur Violine Solo" (DMA diss., University of North Texas, 2011); Yun Jeong Kim, "Isang Yun's Violin Concerto No.1 (1981): A Fuion of Eastern and Western Styles, and the Influence of Taoism" (DMA diss., University of Cincinnati, 2013).

${ }^{5}$ Eunmi Hong, "Isang Yun, His Life and His Music.” (Monthly Keum Ho Magazine 14, 1995); Yong Whan Kim, “ed. Research on Isang Yun.” (Seoul: SiGongSa, 2001).
} 
Yun's study and adaptation of Eastern philosophy and compositional techniques have been explored in articles written by many of the above authors as well. However, much of the writing that exists does not fully explore the Easter philosophies and compositional techniques present in Yun's works. Certain authors have continued to fill those gaps, including Eumni Hong (1995), Yong Whan Kim (2001), Sung Man Choi (1994), and Yun himself alongside Walter-Wolfgang Sparrer (1994). Books by Joon Il Jung (2001), Kyung Dea Jung (2004), and Yoon Kyung Kim (2008) have been particularly useful resources for discussions of Taoism, Yin and Yang, and the Stillness in Motion as applicable to Yun's compositions.

Musical analyses of Yun's compositions are still relatively rare, especially for works featuring solo and chamber flute instrumentation. Fortunately, a number of publications do exist, and those proved extremely helpful in exploring this topic. Concerning Sori for solo flute, there are analytical writings. ${ }^{6}$ Works focusing on Yun's adaptation of traditional Korean music for his own compositional techniques have been writte. ${ }^{7}$ Published analyses of other selected compositions by Yun include the following: on Yun's Etude for flute solo, on Yun's Concerto for flute and small orchestra, and on Yun's Quartet for flutes. ${ }^{8}$

\footnotetext{
${ }^{6}$ Seon Hee Jang, "Interpretation of Extended Techniques in Unaccompanied Flute Works by East-Asian Composrs: Isang Yun, Toru Takemitsu, and Kazuo Fukushima" (DMA diss., California State University Long Beach, 2010); Young Whan Kim, "ed. Research of Isang Yun" (Seoul:SiGongSa, 2001); Seo Young Sun, "A Study of Traditional Compositional Techniques of Sori for Flute Solo (1988) by Isang Yun" (MM thesis, Chang Won University, 2013); Yun and Walter-Wolfgang Sparrer, "ed. My Way, My Dream and My Music" (Seoul: Hice, 1994); Soo Jung Kang, "A Study of Etudes for Flute Solo by Isang Yun." (MM thesis, Catholic University, 2005); and Jae Ryoung Na, "A Study of Isang Yun's Selected Flute Pieces" (DMA diss., Seoul National University, 2015).

${ }^{7}$ Heeyeon Julia Kim, "Isang Yun's Duo for Viola and Piano and Korean Traditional Music" (DMA diss., Florida State University, 2014); Joo Won Kim, "The Development of Contemporary Korean Music with Emphasis on Works of Isang Yun" (DMA diss., The Ohio State University, 2011); Ji Sun Choi, "The Merging of Korean Traditional Music and Western Instrumentation as Exemplified in Four Chamber Works for Piano Composed by Isang Yun" (DMA diss., University of Miami, 2007); Sophia Ro, "Reading Isang Yun's Concerto No. 3 Beyond Western National Norms" (DMA diss., University of North Texas, 2014); Eun Mi Hong, "Isang Yun, His Life and His Music" (Monthly Keum Ho Magazine 14, 1995, p.24), Soo Jung Kang, "A Study of Etudes for Flute Solo by Isang Yun" (MM thesis, Catholic University, 2005); Han Beom Seo, "A Study of Korean Traditional Folk Music" (Seoul: TeaRim Sa, 2009). ${ }^{8}$ Young Sun Seo, “A Study of Traditional Compositional Technqieus of Sori for Flute Solo (1988) by Isang Yun “ (MM thesis, Cahng Won University, 2013); Kim, ed. Research of Isang Yun (Seoul: SiGongSa, 2001); Yun and Walter-Wolfgang Sparrer, ed. My Way, My Dream and My Music (Seoul: Hice, 1994); Na, “A Study of Isang Yun's Selected Flute Pieces" (DMA diss., Seoul National University, 2015); Kim, "Multicultural Influcnes in the Music of
} 
The aforementioned authors have provided a good body of recently-published literature that offers a clear perspective on Yun's musical background, as well as his study of philosophy and his development of unique compositional theories influenced by traditional Korean music.

Isang Yun as Represented in His Concerto for Flute and Small Orchestra” (DMA diss., University of Alabama, 2009); Kang Seok Jung, "An Analysis of Concerto for Woodwinds by Isang Yun” (MM thesis, Cahng Won University, 2004); Jea Ryoung Na, “A Study of Isang Yun’s Selected Flute Pieces” (DMA diss., Seoul National University, 2015). 


\title{
Chapter 2
}

\section{Life and Musical Background of Isang Yun, and Lists of His Flute Works}

\author{
Life and Musical Background of Isang Yun
}

\section{Korean Period}

Isang Yun was born in 1917, the eldest son with two younger brothers and three younger sisters, in Duksan Myeon, Sancheong Gun, South Gyeongsang Province. ${ }^{9}$ In 1920, when he was four years old, he moved to Tongyeong, South Gyeongsang Province, where he spent his youth and completed his elementary and high school education. Familiarity with Yun's childhood in Tongyeong is crucial to understanding his musical exposure and, later, his musical style. Yun once said, "All my artistic, philosophical, and aesthetic traditions originated in my country."10 While a child in Tongyeong, Yun's eyes and ears were exposed to music in new ways, and he began to hear and feel with a composer's attitude. He was surrounded by the folk songs his mother and neighbors sang: the fishermen's songs, Buddhist monk's song, and shamanic song. ${ }^{11}$

Beginning at the age of five, in part due to his father's opposition of Japanese presence in Korea and modernizing influences of the time, Yun studied at a Korean-language school. During this period, he also regularly attended the local chapel, where he studied composition, violin, guitar, and other creative fields. Later, as a working adult, he traveled to Seoul to study music theory with violinists in a military band. While in Seoul, he was exposed to and began studying

\footnotetext{
${ }^{9}$ Yong Whan Kim, Research on Isang Yun (Seoul: SiGonSa, 2001), 20.

${ }^{10}$ Ear-Ryung Lee, Communication with World Famous People (Seoul: Moon Hwa Sang Sa, 2004), 184.

${ }^{11}$ These songs are spread by mouth to mouth. There is no specific information regarding these songs.
} 
musical scores from Western music, especially the works of Richard Strauss (1864-1949) ${ }^{12}$ and Paul Hindemith (1895-1963). ${ }^{13}$ However, by 1935, Yun began to feel restricted in studying composition only and so elected to return to Tongyeong when he received permission from his parents to enroll in the Osaka Music Academy in Osaka, Japan. There, he continued to study composition and began to learn to play the cello.

In 1940, Yun returned to Japan and studied composition with Ikenouchi Tomojiro (19061991 $)^{14}$ in Tokyo. Ikenouchi Tomojiro was one of the first Japanese students to study at the Paris Conservatory of Music; he later became a professor of composition at the Tokyo Music Arts University and earned notoriety by teaching many well-known composers and sending his students to the Paris Conservatory. However, Yun made a rather sudden decision to return to Korea after the Pacific War in 1941 and was arrested in July of 1944 for planning an independence movement. Two months after his arrest, Yun escaped back to Seoul from Tongyeong, South Korea for fear of being arrested again. As the war drew to a close, he was admitted to the hospital with pulmonary tuberculosis and later left Seoul for a second time. ${ }^{15}$

In 1945, Yun returned home to Tongyeong as a high school music teacher. On September 15, 1945, a group of artists established the Tongyeong Culture Association with the goal of creating a national culture. Members of this group included Yun, novelist Park Kyongni (1926$2008)^{16}$, poet Kim Chunsoo (1922-2004) ${ }^{17}$, and poet Yoo Chihwan (1908-1967). ${ }^{18}$ In addition to his work with the TCA, Yun served as the director of an orphanage for nearly a year, caring for

\footnotetext{
${ }^{12}$ Richard Georg Strauss (1864-1949) was a leading German composer of the late Romantic and early modern eras.

${ }^{13}$ Paul Hindemith (1895-1963) was a prolific German composer, violist, violinist, teacher and conductor.

${ }^{14}$ Ikenouchi Tomojiro (1906-1991) was a Japanese composer of contemporary classical music and professor, born in Tokyo, Japan.

${ }^{15}$ Name unknown, "History of Yun and his musical life", (naver.com, May 04, 2012) http://blog.naver.com/pianosampjh/110137686112).

${ }^{16}$ Pak Kyongni (1926-2008) was a prominent South Korea novelist.

${ }^{17}$ Kim Chunsoo (1922-2004) was a prominent South Korea poet.

${ }^{18}$ Yoo Chihwan (1908-1967) was a prominent South Korea poet and educator.
} 
children who had been orphaned during Pacific War. ${ }^{19}$ In 1947, he formed the Tongyeong String Quartet with the intent of contributing to the development of local culture. After a period of time, Yun relocated to Busan, where he met and married his wife, Su Ja Lee (b. 1927).

Beginning in 1951, Yun taught composition at Seoul National University and DukSung Women's University. In 1954, he became a standing member of the newly created Korean Composers Association. Yun also joined the Seoul Music Association, participating in various art festivals and emerging as a composer with a strong focus on the Korean music scene. However, during the period after the Korean War, the musical world became polarized between the South and the North. When the emancipation occurred, many nationalistic songs were banned in response to this conflict, ${ }^{20}$ leading to a much wider acceptance of Western Music within the Korean Peninsula. Throughout this time, Yun, who was actively composing, received recognition for his "String Quartet No. 1" and his "Piano Trio" in April 1956. Then, at the age of forty, Yun returned to Paris to study the newest composition techniques in Europe.

\section{European Period}

Yun entered the Paris Conservatory of Music in 1956, determined to feed his passion for music by learning the latest serialist techniques. Composition was taught at the conservatory at this time by Tony Louis Alexandre Aubin (1907-1981) ${ }^{21}$ while Pierre Revel taught music theory. ${ }^{22}$

\footnotetext{
${ }^{19}$ World War II, also known as the Second World War, was a global war that lasted from 1939 to 1945 , although related conflicts began earlier.

${ }^{20}$ The Korean War began when North Korea invaded South Korea. Korea was ruled by Japan from 1910 until the closing day of World War II.

${ }^{21}$ Tony Louis Alexandre Aubin (1907-1981) was a French composer.

${ }^{22}$ Pierre Revel (1901-1984) was a French composer,
} 
Other composers who had an impact on Yun before he traveled to Europe include Bela Bartok (1881-1845), ${ }^{23}$ Richard Strauss (1864-1949), and Claude Debussy (1862-1918). ${ }^{24}$

Yun believed that Igor Stravinsky's (1882-1971) ${ }^{25}$ dynamic rhythm was too tight, and that the dodecaphonic technique espoused by Arnold Schoenberg (1874-1951) ${ }^{26}$ was too rational, rather than emotional. Conversely, Bartok's innovations and power, the colorful orchestra of Strauss, and the tone colors of Debussy all fascinated him; Debussy, in particular, resonated with Yun's musical interests. Unfortunately, Tony Aubin eventually refused to accept his pupil's compositional preferences, and Yun was forced to live in financial difficulty for a time in Paris. He moved to Germany in 1957, where he studied Reinhard Schwarz-Schilling's (1904-1985) ${ }^{27}$ methods of counterpoint and fugue. While there, he wrote compositions for Boris Blacher (19031975) ${ }^{28}$ and Joseph Rufer (b.1926); Blacher had lived in China when he was younger, and thus had a relatively open mind regarding other cultures. He encouraged Yun's attempts to engage with the concepts and sounds of East Asian music.

During this time period, serialist techniques tended to dominate German musical thought and composition, as did Arnold Schoenberg's disciple Anton Webern (1883-1945). ${ }^{29}$ But beginning the in $1950 \mathrm{~s}$, the discourse underwent a gradual shift. As serialism began to fade out of the limelight, Yun struggled with his own ongoing quest for a musical identity and position. Over time, he began to think more about how to integrate his own composition techniques and musical

\footnotetext{
${ }^{23}$ Bela Bartok (1881-1945) was a Hungarian composer and pianist. He is considered one of the most important composers of the $20^{\text {th }}$ century.

${ }^{24}$ Claude Debussy (1862-1918) was a French composer.

${ }^{25}$ Igor Stravinsky (1882-1971) was a Russian-born composer, pianist, and conductor. He is widely considered one of the most important and influential composers of the $20^{\text {th }}$ century.

${ }^{26}$ Arnold Schoenberg (1874-1951) was an Austrian composer, music theorist, and painter. He was associated with the expressionist movement in German poetry and art, and leader of the Second Viennese School.

${ }^{27}$ Reinhard Schwarz-Schilling (1904-1985) was a German composer.

${ }^{28}$ Boris Blacher (1903-1975) was a German composer and librettist.

${ }^{29}$ Anton Webern (1883-1945) was an Austrian composer and conductor.
} 
aesthetics with European ones. While in Germany, he finished music for Seven Instruments (1959). This piece is not necessarily radical, but it resonates with a unique Asian character. This amalgamation of aesthetics began to earn Yun notice in the European contemporary music scene. He was particularly notable for being the first composer to try to develop a major sound technique based on Korean musical traditions, as seen in the second movement of music for Seven Instruments.

Yun's life became more stable in 1961, when his wife joined him in Germany. A few representative works that embody his compositional style during this period include Gasa for violin and piano and Garak for flute and piano. These two pieces for violin and flute were created with Yun's main tone technique and main sound technique in mind, both of which were influenced by traditional Korean music. "Gasa" means lyric in Korean, and "Garak" means melody.

Yun traveled to North Korea during 1963, to visit a friend in Pyongyang: Choi Han, with whom he had studied in Japan in the midst of Japanese colonial rule. He later paid more than twelve visits to North Korea's Mission and Safety House. Yun was motivated to visit North Korea by three main causes at this time: he wanted to spend time with his dear friend and be there for him at the time of his death, he considered North Korea his second homeland during this post-war period, and he felt compelled to see a work of art, "Ghost (Sa Sin-Do)" by Jangseo, in North Korea while he could, due to the fact that the post-war division of the country meant that one day he would no longer have access to North Korea. ${ }^{30}$

However, while in North Korea, Yun was kidnapped and detained as a German operative infiltrating Korea; during his time in prison, he was subjected to both psychological and physical

\footnotetext{
${ }^{30} \mathrm{Sa}$ Sin-do are ancient tomb paintings from the late Gogureyo.
} 
torture. ${ }^{31}$ While imprisoned, he attempted to commit suicide but failed, after which he was given the opportunity to compose and subsequently completed his opera, Ein Schmetterlingstaum (1986). The completed work was brought to Germany by his wife, who was released earlier on probation, and it premiered on February 23, 1969, at the Nuremberg Opera Theater, under the title Die Witwe des Schmetterling (1968). The opera received very favorable responses, including thirty-one curtain calls at the premiere. ${ }^{32}$ At the same time, however, Yun was admitted to the hospital due to his deteriorating health in prison; however, he did not stop composing during his period of hospitalization.

When news of his capture and detainment spread, a campaign for his release was gradually mounted around the world. Composers Igor Stravinsky, Elliott Carter (1908-2012), ${ }^{33}$ and Herbert von Karajan (1908-1989) ${ }^{34}$ became the main organizers of the effort, recruiting approximately 200 musicians and other well-known figures to sign a petition for Yun's release. With the help of this sustained global effort, Yun was released back to Germany as a special envoy in February 1969.

Yun's compositional style underwent notable changes around 1970. After Images, which he composed in 1968, he developed a clearer compositional tone for individual musical instruments. This tendency towards tonal clarity is also evident in the Etudes for flute solo (1974). After 10 years of suffering in prison, Yun struggled renew himself artistically, writing music that exhibited his own unique sound techniques and become publicly recognized as a global artist. As part of his attempt to relate to different populations around the world with his art, he tried to make music that was easier to write. He put special effort into revising his "main-tone technique"

\footnotetext{
${ }^{31}$ The East Berlin Affair (Dong Beak Rim affair) was happened between 1967 and 1969, involving Isang Yun, who was one of the artist who was kidnapped and released.

32 Eunmi Hong, "Isang Yun, his life and his music," Monthly Keum-ho Magazine Vol. 14 (December 1995), 50-51.

${ }^{33}$ Elliott Carter (1908-2012) was an American composer who was twice awarded the Pulitzer Prize.

${ }^{34}$ Herbert von Karajan (1908-1989) was an Austrian conductor. He was principal conductor of the Berlin Philharmonic for 35 years.
} 
(Haupttontechnik), developed in the early 1960s and utilized through the late 1970s, seeking a directness of expression that would make it easily accessible to the public. His musical structures, which were extremely complicated and difficult to understand, gradually simplified, as he composed with a softer and clearer result in mind.

The Cello Concerto (1972) is an example of a composition that displays interaction between the solo instrument and the orchestra, indicating a new development in Yun's work. The Cello Concerto also represents the beginning of a new creative period of Yun. During this period, he wrote pieces aimed at conveying messages through clear and concise textures and pursued an ideal mode of social expression. ${ }^{35}$ Later, in the 1980 s, he gradually developed his concept of form to become more flexible, especially in tempo, which would later come to result in an increased freedom in his ability to compose works for large ensembles. As a result, Yun began to write more extensive concertos and symphonies, with one of his main goals centering on communicating with his audience through these genres. ${ }^{36}$ Yun sought the beauty of sublimation within scale and texture, while seeking to determine the effect of the title music on the framework of a symphony.

Isang Yun's compositions, written over a span of 39 years in Europe, generally fall into purely instrumental genres rather than vocal ones. This phenomenon is the result of a composer who has freed himself from the Western traditional genres that many composers were limited by the 18th century. On September 17, 1994, Yun wrote The Angel in the Flame for Orchestra (1994) to commemorate students who committed suicide due to academic stress or financial pressure. One year later, on November 3, 1965, he died of pneumonia at the Berlin Hospital in Germany. ${ }^{37}$

\footnotetext{
${ }^{35}$ YoungSun Seo, “A study on traditional compositional techniques of Sori for flute solo (1988) by Isang Yun" (Master's thesis, Changwon National University, 2013), 26-27

${ }^{36}$ Seo, "A study on traditional compositional techniques of Sori for flute solo (1988) by Isang Yun" (MM thesis, Changwon National University, 2013), 30

${ }^{37}$ YoungSun Seo, "A study on traditional compositional techniques of Sori for flute solo (1988) by Isang Yun" (MM, Changwon National University, 2013), 34
} 


\section{Lists of Isang Yun's Flute Works}

This list of Isang Yun's Flute works is arranged by date of composition. All works are included: solo, accompanied, quartet, quintet, chamber pieces, and opera.

\begin{tabular}{|c|c|c|}
\hline Year & Name and Instruments & Information \\
\hline 1959 & $\begin{array}{c}\text { Music for Seven Instruments } \\
\text { (Flute, Oboe, Clarinet, Bassoon, Horn, Violin, } \\
\text { and Cello) }\end{array}$ & $\begin{array}{l}\text { Premiered at the International Summer } \\
\text { Courses of Contemporary Music in } \\
\text { Darmstadt, Germany }\end{array}$ \\
\hline 1963 & Garak for Flute and Piano & $\begin{array}{l}\text { Premiered in Berlin on September 11; } \\
\text { 196, performed by Karl-Bernhard Sebon } \\
\text { and Horst Gobel. }\end{array}$ \\
\hline 1968 & Images for Flute, Oboe, Violin, and Cello & \\
\hline 1971 & $\begin{array}{c}\text { Opera Geisterliebe (Love of Spirits) } \\
\text { (Flute, Alto, and Piccolo) }\end{array}$ & \\
\hline $1972-73$ & $\begin{array}{c}\text { Trio for Flute (or Alto Flute), Oboe, and } \\
\text { Violin) }\end{array}$ & \\
\hline 1974 & Etudes for Flute Solo & $\begin{array}{l}\text { Dedicated to Gunter and Ursula } \\
\text { Freudenberg. Professor Chang-Guk Kim } \\
\text { performed the first part of the work in } \\
\text { Kyoto, Japan on July } 18,1974 \text {, and } \\
\text { performed by Beate Gabriela Schmidt in } \\
\text { Berlin, Germany on November } 3 \text { of the } \\
\text { same year. }\end{array}$ \\
\hline 1977 & Concerto for Flute and Small Orchestra & $\begin{array}{l}\text { Commissioned by the Musicktage } \\
\text { Hitzacker and premiered in Germany } \\
\text { with a performance by flutist Karl Heinz } \\
\text { Zoller, a principal flutist in the Berlin } \\
\text { Philharmonic. }\end{array}$ \\
\hline $1977-78$ & Salomo for Alto Flute (or Flute) & \\
\hline 1980 & Novellette for Flute (or Alto Flute) and Harp & \\
\hline \multirow[t]{2}{*}{1986} & Quartet for Flutes & $\begin{array}{l}\text { Performed during the } 36^{\text {th }} \text { Berlin Festival } \\
\text { by Dagmar Becker, Renate Greiss- } \\
\text { Armin, Gaby van Riet-Pas, and } \\
\text { Roswitha Stage. }\end{array}$ \\
\hline & Quintet for Flute and String Quartet & \\
\hline
\end{tabular}




\begin{tabular}{|l|r|l|}
\hline 1988 & 'Sori' for Flute Solo & $\begin{array}{l}\text { Premiered at Carnegie Hall in New } \\
\text { York, with a performance by Roberto } \\
\text { Fabriziani on September 9, 1988 }\end{array}$ \\
\cline { 2 - 3 } & Invention for Two Flutes & \\
\cline { 2 - 3 } & Pezzo Fantasioso for Flute and Violin & \\
\cline { 2 - 3 } & Quintet for Flute, Violin, Cello and Piano & \\
\hline & Festlicher Tanz for Woodwind Quintet & \\
\hline & Woodwind Quintet & \\
\hline
\end{tabular}




\section{Chapter 3}

\section{Eastern Philosophy and Compositional Techniques in Yun's Music}

\section{Eastern Philosophy}

The music of Isang Yun has a spiritual foundation in Taoist philosophy, connecting the music with the natural universe. Yun defined his music as a part of the universe. ${ }^{38}$ However, Taoist philosophy is not the sole inspiration for his music. Studies of his life and music have neglected other philosophical movements which influenced both Yun and Korean culture, namely Confucianism and Buddhism. ${ }^{39}$ According to files kept in the Mayor's Office in Tongyeong, he participated in neighborhood ceremonies such as the Lantern Festival, a common experience for many Koreans whose culture were influenced by Confucian, Taoist, and Buddhist thought. ${ }^{40}$ Yun naturally absorbed these ideas as he heard them growing up due to his exposure to these notions at a young age. In addition to subscribing to East Asian ideology, Yun was a humanistic spirit who sought a spiritual foundation for his music. Throughout his life, Yun did his best to represent various political and social problems within his music.

\footnotetext{
${ }^{38}$ YoungSun Seo, "A study on traditional compositional techniques of Sori for flute solo (1988) by Isang Yun" (Master's thesis, Changwon National University, 2013), 31-32

${ }^{39}$ Sung-man Choi and Eunmi Hong, Isang Yun's history of music life (Seoul: Hangil-sa, 1994), 68-110.

${ }^{40}$ Choi and Hong, Isang Yun's history of music life (Seoul: Hangil-sa, 1994), 82.
} 


\section{Ideology of Taoism}

Taoism first appeared in China around $2500 \mathrm{BCE}$, arriving alongside Confucianism as an alternative to the time period's social chaos. This movement, which was founded by ancient Chinese philosopher and writer Laozi and promoted by his eldest son, shares many ideas with Confucianism and ancient spiritual traditions. All three found common ground on such topics as humanity, society, monarchy, heaven, and the nature of the universe. However, Confucianism was founded with an interest in the moral and political system of China, while the ideology of Taoism maintains a more individualistic and metaphysical approach that encompasses cosmology, theories of humanity, epistemology, poetry, and politics. As the work of a man who was interested in all forms and methods of creation, Yun's music has a cosmic element that is strongly related to Taoist ideology. ${ }^{41}$

There are three central elements of Taoist cosmology. The first element is expressed by the phrase, "what is so of itself." It is a concept opposed to artificiality as a fundamental characteristic of the human state. In this ideology, the term "innocence" refers to a pure act that is not unnatural, nor the product of neglect. In this philosophy, all naturally created things come from nothing and return to a state of nothingness, experiencing states of change in their being throughout their existence. Laozi stated, "Everything flourishes and returns to the root of oneself." ${ }^{42} \mathrm{He}$ further said, "All things are born from the frame of change and all are returned by the framework of change." ${ }^{43} \mathrm{He}$ looked to nature as a model of these truths and patterns, which is why nature is viewed as the foundation of "what is so of itself" in this philosophy. ${ }^{44}$

\footnotetext{
${ }^{41}$ Joon-il Jung, Introduction to Taoism (Seoul: Seok Chang Sa, 2001), 50.

${ }^{42}$ Jung, Introduction to Taoism, 52.

${ }^{43}$ Jung, Introduction to Taoism, 53.

${ }^{44}$ Jung, Introduction to Taoism, 39.
} 
The second element concerns the greatest power of creation, which is the ability to produce all things. Two separate energies, Yin and Yang, combine to produce all things, and later, all things eventually become extinct. Laozi explains that everything comes from one initial singularity. Birth from this first "one" turns from the road of a fixed thing, or enters a state of change: one gives birth to two, two give birth to three, and three give birth to all things. "Here, one refers to the state of unity; the two are the states of harmony." the root, also known as the root of reality; furthermore, all things are differentiated from one, and all things come from the initial creation. ${ }^{46}$

The third element is the concept of eternity, which explains that all things actualize and recede from their extremes and return to the original state of nothingness but do not cease to exist. Eternity is what allows the cycle to remain in place forever. All things in nature come from the initial creation and become all things before returning to nothing but are also maintained forever. As Laozi stated, "Everything flourishes and returns to the root of oneself." ${ }^{47}$ In Taoist ideology, the creation and extinction of all things are like the coming of the night when day is over. Life and death are the same: death is not the end. This is also related to the concept of "stillness in motion." In Eastern thought, there are no concepts of universal limits or a final endpoint: there is only a physical reaction when energy moves from the cathode, through the copper, to get to the anode.

This Taoist principle is expressed several times in the works of Isang Yun. Yun's Sori for flute is an example of a piece influenced by Taoist concept, especially the ideas surrounding birth and death.

\footnotetext{
${ }^{45}$ Jung, Introduction to Taoism, 45.

${ }^{46}$ Jung, Introduction to Taoism, 49.

${ }^{47}$ Jung, Introduction to Taoism, 52.
} 


\section{Yin and Yang}

The theory of "Yin and Yang" attempts to explain the changes and growth of all things in the universe as functions of yin and yang, defined as two separate groups. Yin and Yang theories were formed during the Han dynasty ${ }^{48}$ and have since been developed into a spiritual science, based on the changes in the universe and human fate.

Yin and Yang are two groups. Yin is cold, dark, static, internal, and imparts a slowing sensation, while Yang is warm, bright, dynamic, outgoing, and fast-moving. Yin and Yang are oppositional, but also intertwined. If the two are separated, the balance is broken and their union cannot produce all things. According to Taoist philosophy, Yin and Yang cannot generate anything independently, and worldly material can only be created by an interdependent relationship. Yin and Yang may be opposites, but they function as mutual essentials in the creation and harmony of nature. ${ }^{49}$

Isang Yun appears to have utilized the principle of Yin and Yang when composing melodies. For example, both elements would be present in a melody that draws to a quite close (evoking Yin) but displays a strong rhythmic pattern (representing Yang). This relationship manifests in various ways: through the presence of vibrato or Nonghyun, ${ }^{50}$ the use of continuous tone and ornamentation, or the ascension and decrease of sound and intensity of pitch. Yin and Yang are especially present in Yun's Sori, as part of its lengthy melodic ideas.

\footnotetext{
${ }^{48}$ The Han dynasty (Han Chao) was the second imperial dynasty of China (206 BC- 220 AD), preceded by the Qin dynasty (221-206 BC) and succeeded by the Three Kingdoms period (220-280AD).

${ }^{49}$ Kyung Dae Jung, "Yin and Yang” (Seoul:Seong Bo Sa, 2004), 22.

${ }^{50}$ Nonghyun is a vibrato played in Korean traditional music, especially on string instruments.
} 


\section{Stillness in Motion}

The word "motion" in the phrase "stillness in motion" carries associations of quiet, cleanliness, clarity, and rest. "Stillness" implies action, living, feeling, and changing. For example, there are many galaxies in the universe: we live in our galaxy alongside many planets, while many people live on Earth and microorganisms live inside many creatures. All of this is moving constantly, though from a distance it appears to be stopped or still. Stillness in motion can be interpreted as "quiet on the surface," though it can also be understood as a constant center with detailed movement. From a Taoist perspective, all things are related to each other, so all things are in parts, and parts are in all things - a point of view that appears several times in the musical aesthetic of Isang Yun. ${ }^{51}$ In Yun's own words, "Each of the smaller musical forms must contain the basic idea of the whole work.... And every single piece of my work must contain the whole of my music world." 52

Isang Yun himself is an amalgamation of his entire collection of works; likewise, each musical work of his is a microcosm of all of the 150 pieces he composed. From this perspective, the smallest elements of his music are not necessarily the basic material for a larger structure, but part of the flow of his overall musical process. Yun's music features various forms of “stillness in motion," since there are many ways to express the same sound without the movement of the pitch: these include pitch bending, tremolo, vibrato, and glissando.

\footnotetext{
${ }^{51}$ Yoon Kyung Kim, “Eastern philosophy on 'Gasa' for violin and piano by Isang Yun” (MM thesis, Kyongwon Univeristy, 2008), 17

${ }^{52}$ Isang Yun and Walter-Wolfgang Sparrer, My Way, My Ideal, My Music (Seoul: Hice, 1994), 321.
} 


\section{The Spirit of Humanism}

A composer is a human before he Is an artist. The composer can't just look at the world the same. Pain, oppression, humiliation and injustice are everywhere. All of these come into my mind.... Where there is pain, where there is injustice, I will speak with my music.

$$
\text { -Isang } \text { Yun }^{53}
$$

In addition to being a composer, Isang Yun was a humanist, who believed very strongly in the language of music. He was never deeply interested in the technical aspects of sound. Even after he moved to Europe and began composing there, he did not concentrate on incorporating East Asian styles or forms. Instead, his use of traditional Korean musical elements and acoustics was meant to express something transcendental and universal. This was particularly true in works he composed after the mid-1970s. ${ }^{54}$

Fundamental concepts of East Asian art, philosophy, and politics play an important role in the music of Isang Yun; however, an artist's expressions of political opinions and perspectives is not a uniquely East Asian practice, but rather a human one. East Asian music is not a "representation" of individual Confucian scenes, objects, or phenomena: it is a prelude to the practice of universal discipline, logic and order. It can also be said to be an expression, though never a subjective one. Eastern art is universal, not personal. It emphasizes a feeling that can find objective harmony with the heaven and earth. Korean music is considered one with life, which contradicts the context of an artist's conscious expression of both music and non-musical material. In an East Asian worldview, everything is seen as "one," including music and other non-musical

\footnotetext{
${ }^{53}$ Isang Yun and Walter-Wolfgang Sparrer, My Way, My Ideal, My Music (Seoul: Hice, 1994), 233.

${ }^{54}$ YoungSun Seo, "A study on traditional compositional techniques of Sori for flute solo (1988) by Isang Yun" (MM thesis, Changwon National University, 2013), 39
} 
fields. Subsequently, it was through the Western humanistic tradition that Isang Yun attempted to express his mental and socio-critical consciousness. ${ }^{55}$

Although Yun's humanistic attitude towards art has much in common with Western tradition, that does not mean it should be analyzed according to all Western traditions. He favored a uniquely-synthesized compositional style that drew upon inspiration from both Western concepts (humanism) and East Asian concepts (Ying and Yang, stillness in motion, and Taoism).

${ }^{55}$ Yong Whan Kim, Research on Isang Yun (Seoul: SiGonSa, 2001), 63. 


\section{Compositional Technique}

Isang Yun spent ten years in Europe exploring ways to combine Korean musical concepts with the musical language he was developing in Paris and Germany. In Paris, Yun studied with Tony Aubin and Pierre Revel; he was also influenced by Béla Bartok, Richard Strauss, and Claude Debussy. The twelve-tone technique, first espoused by Arnold Schoenberg, also had an impact on Yun's work. It was thought to be rational rather than emotional, a distinction that proved influential in the creation of Yun's compositional technique Haupttontechnik, or "main tone technique."

Yun moved to Germany in 1957, where he studied Reignard Schwatz-Schilling's counterpoint and fugue form. At that time, the musical world in Germany was dominated by Schoenberg's twelve-note method, but after 1960, the aesthetic current began to gradually change direction. As the post-tonal experiments had been underway for decades before Yun's arrival in Europe, he struggled to form a musical identity and establish himself amid these avant-garde initiatives. Subsequently, Yun began to think more about his own compositional techniques and musical aesthetics. Over time, Yun sought to use and create compositional techniques related to a traditional Korean musical styles and to the aforementioned movements of East Asian philosophy. What follows is a brief survey of the techniques developed by Yun, after which will be a detailed analysis of how these techniques are employed in Sori (Chapter 4) and employed in other flute works by Yun (Chapter 5). 


\section{Main Tone Technique (Haupttontechnik)}

Yun described the main-tone technique as "the foundation of my music language." ${ }^{, 56}$ This method is driven by the concept that, in the composition of music, there is one central and single tone or sound which is constantly being altered by the surrounding sounds. Yun's musical works are not composed of a group of individual sounds into a single unified sound; instead, they consist of a sound or a group of sounds that are decorated with the sonorities of surrounding tones to form the core of the work.

Yun further described this technique further during a 1993 lecture at the Mozarteum in Salzburg:

These terminologies help to explain my compositional techniques in more generalized terms, establishing an ideological base for my treatment of a tone or a group of tones that are organized by a center that is colored by ornamental tone movement: The basis of my composition is "Einselton" (a single tone). Each tone, invoking the power of a chameleon, becomes a foundation along with ornamentations, vibratos, accents, glissandos which envelops the sound unit of a single note. I called this "Hauptton". 57

\footnotetext{
${ }^{56}$ YoungSun Seo, “A study on traditional compositional techniques of Sori for flute solo (1988) by Isang Yun" (MM thesis, Changwon National University, 2013), 46.

${ }^{57}$ Isang Yun, "Uber meine Musik" (lectures given at Hochschule für Musik and darstellende Kunst "Mozarteum" in Salzburg, May 17, 1993), in Isang Yun and Walter-Wolfgang Sparrer, My Way, My Idea, My Music, trans. Kyo-chul Chong and In-Jung Yang (Seoul: Hice, 1994), 25. See also Jeongmee Kim, "Musical Syncretism in Isang Yun's Gasa" Locating East Asia in Western Art Music, ed. Yayoi Uno Everett and Frederick Lau (Wesleyan University Press, 2004), 184.
} 


\section{Main Sound Technique (Hauptklangtechnik)}

The main-sound technique was first used in the second movement of Yun's Music for Seven Instruments, which was composed in 1959. It is based on the traditional music of China and Korea, as well as the main-sound technique, which, in Western music theory terms, is music written based on the following intervals: minor second, minor third, perfect fourth, and perfect fifth. The minor second is the most predominant of these.

While the main-sound technique may be applied in a dramatic way in works for larger ensembles, such as concerti or orchestral pieces, it is most often utilized in chamber settings and small ensembles. Beginning in the late 1970s, Yun modified these major acoustic techniques to make his music more accessible and easier to understand. ${ }^{58}$ Although this technique appeared consistently in Yun's music throughout the 1970s and 80s, later works featured a gradual easing of strict and complicated elements found in earlier works. ${ }^{59}$

\section{Tone Complex (Tonkomplex)}

A tone complex refers to a melismatic cluster of notes, composed of the main note and the surrounding sound. This tone complex's key characteristic is a central core with a changing nucleus. This technique is derived from the main-tone sound of Korean music. One "sound" in Korean traditional music is not a single sound: strictly speaking, it is a composite of several sounds, all part of a very natural changing process of one sound. ${ }^{60}$

\footnotetext{
${ }^{58}$ GangSuk Jeong, "Analysis of Concerto for Clarinet and orchestra” (MM thesis, Changwon University, 2004), 2021

${ }^{59}$ YoungSun Seo, "A study on traditional compositional techniques of Sori for flute solo (1988) by Isang Yun," (MM thesis, Changwon National University,2013), 51-52

${ }^{60}$ Sung-man Choi and Eunmi Hong, Isang Yun's history of music life (Seoul: Hangil-sa, 1994), 242.
} 


\section{Sound Color Composition (Klangfarbenkomposition)}

Widely used throughout Europe in the late 20th century, this tone composition technique recognizes "timbre" as a key element in the creation of music. According to traditional composition techniques, only the "tone height" and "tone value" are important. Beginning in 1955, Yun sought to overcome the limitations of Western music by adapting a new compositional technique pioneered by Gyorgy Ligeti (1923-2006) ${ }^{61}$ and Krzysztof Penderecki (b.1933). ${ }^{62}$ Ligeti and Penderecki created and promoted this technique in response to the limitations of Serialism as they sought additional means of expression. This novel technique gave Yun a way to compose with traditional tones and instruments while remaining emancipated from some of Western music's stricter formal conventions.

\section{Playing Around (Umspielung)}

Musical decoration, or ornamentation, is a sound reinforced by a momentary pulsation; it is characterized by a half-measure, or up to two or three measures. Decorative detours are used to animate the proceeding sounds. Examples, such as the decorative roundabout, can be found in the sigimsae $^{63}$ of Korean traditional music.

Traditional Korean music often employs pitch bending, such as a slight push up, a downward slip, or a return to the original sound. Yun employs the widely-distributed spectrum of glissando, clustering, trill, vibrato, quadruple slip, and tone changes to decorate the main tones each time. In Korean music, the decorative detour emphasizes the life of the main sound, as well

\footnotetext{
${ }^{61}$ Gyorgy Ligeti (1923-2006) was a Hungarian composer of contemporary classical music.

${ }^{62}$ Krzysztof Penderecki (b. 1933) is a Polish composer and conductor.

${ }^{63}$ Sigimsae is a Korean traditional ornamentation music technique.
} 
as providing it with constant energy; the dynamism of these sounds constitutes a major feature of Yun's music.

The following chapter provides an analysis of Sori for flute, which Yun composed using various Eastern philosophies and compositional techniques. The design of the composition will be thoroughly examined, as will its inclusion of Korean musical techniques and incorporation of Yun's Eastern influences. 


\section{Chapter 4}

An Analysis of Isang Yun's Sori for flute solo (1988)

\section{Composition and Characteristics of Music}

Sori was composed as a flute solo in 1988 and premiered at New York's Carnegie Hall on September 9, where it was performed by Roberto Fabbriciani (b.1949). ${ }^{64}$ This work is a single movement with 126 measures, divided into three parts, according to changes of tempo. This is a form often seen in the works of Isang Yun and is considered to give a sense of stability of the tempo of his music. This research paper divides Sori into three sections, as divide by tempo; "ca," which in Latin means "approximately," accompanies the tempi. This represents an increased flexibility in the tempo of a work, where important musical aspects are not finalized by the composer but are handed over to the performer who may interpret them freely. Yun encourages the performer to create the rhythm and timing freely, a compositional technique well-suited to the flexible tempo of Yun's music.

Chart 1: Form of Sori for flute solo

\begin{tabular}{|c|c|c|}
\hline Section & Measures & Tempo \\
\hline Section 1 & $1-15$ & $\mathrm{~J}=$ ca 76 \\
\hline Section 2 & $16-72$ & $\mathrm{~J}=$ ca 60 \\
\hline Section 3 & $73-126$ & $\mathrm{~J}=$ ca 52 \\
\hline
\end{tabular}

${ }^{64}$ Roberto Fabbriciani (b. 1949) is an Italian flutist. 


\section{Section 1}

The first section is 15 measures in length is indicated at a tempo of eighth notes at ca. 76 . Throughout Through this "ca," Yun encourages the performers to set the rhythm and timing freely. ${ }^{65}$ Additionally, since the work is defined by principles regarding the change in the length or center of the sound complex (Tonkomplex), this is relatively long as compared with most cases; thus, the tempo of the entire work is generally slow. This reflects Yun's Taoist influence: rapid movement on a detailed level that may appear as no movement from a broader perspective. It looks very busy in the musical notation, but the resulting sound is a slow song in context of the beat. Measures 14 to 15 bring the first section of Sori to a close, with the final sonority of this section fading away with $p p p$, creating a flexible transition to the second part.

Example 1: Isang Yun, Sori for flute solo, measures 14 and 15

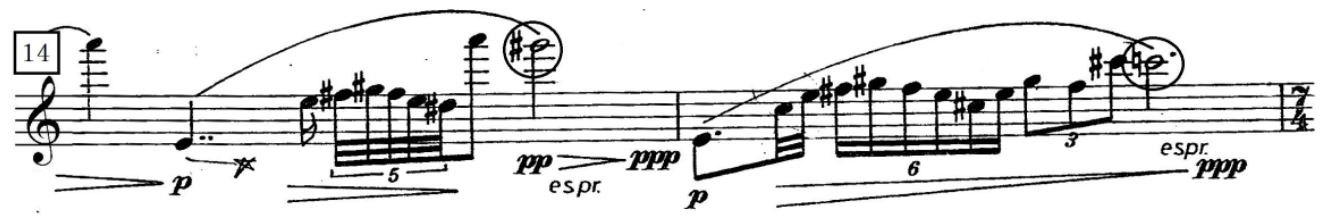

\footnotetext{
${ }^{65}$ Mikyung Lee, “Music and Korea,” Magazine of Korean Arts 22 (2001), 1.
} 


\section{Section 2}

The second section consists of 57 measures, ranging from mm. 25-72. "Ca" again makes this section flexible, depending on the interpretive capacity of the performer. The tempo of this section is slower than that of the first, and it uses a variety of effects, such as frequent changes in pitch and differential sound, to make the oscillation of notes far more active and create a faster feel in this section. At this point, scattered sounds and quick, short textures create a fragmented piece of music. Brief ornaments and accents that appear throughout the work are also featured here. This section exhibits characteristics of Korean music: specifically, Yun imitates the rhythm and sound of a Korean flute daegeum, ${ }^{66}$ using several extended flute techniques.

The end of the second section, measures 69 through 72, is strikingly different than the opening, marked by a vigorous trill, followed by the main tone, and ending with various decorative ornamentations before a fermata. The ending to this section contrasts the end of the first section, which served as a seamless connection into this middle section.

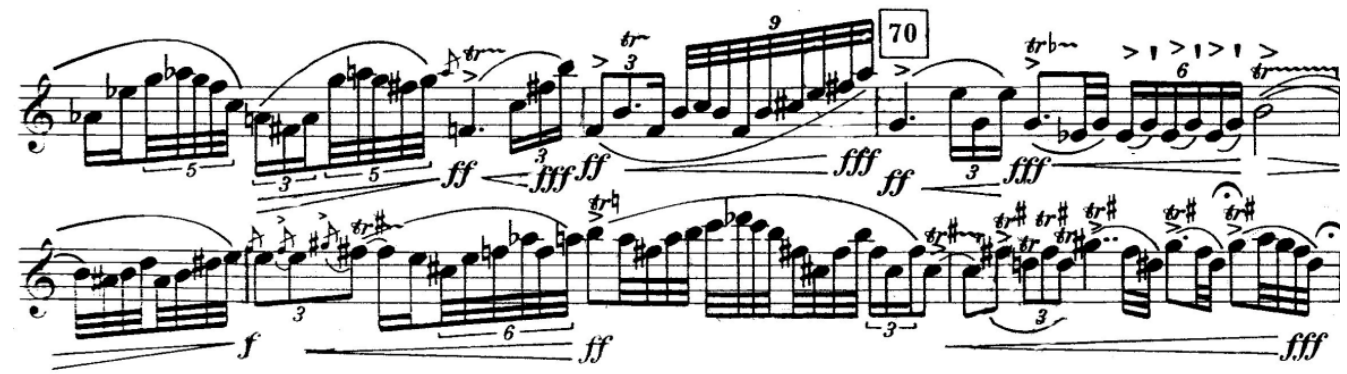

\footnotetext{
${ }^{66}$ Daegeum is a Korean Traditional Flute.
} 


\section{Section 3}

The third section, consisting of 53 measures, returns to a slower tempo with fast rhythmic material. This section conveys the Taoist concept of "stillness in motion." Regarding ornamentation and rhythmic activity, the opening section employs far more decoration with the main tone sound and traditional Korean musical elements such as accents on the trill. These ornaments are rarely used in Section 3, and the main tone(s) are presented almost directly, emphasizing instead the expression of the tone through the change in the pitch and the differential sound. This part look different than the previous part, but shares a basis in Taoism: the same elements appear in Section 1, and their reappearance in Section 3 gives the piece a sense of unity (see Examples 3 and 4).

Example 3: Similarity of ornaments between Section 1 and Section 3

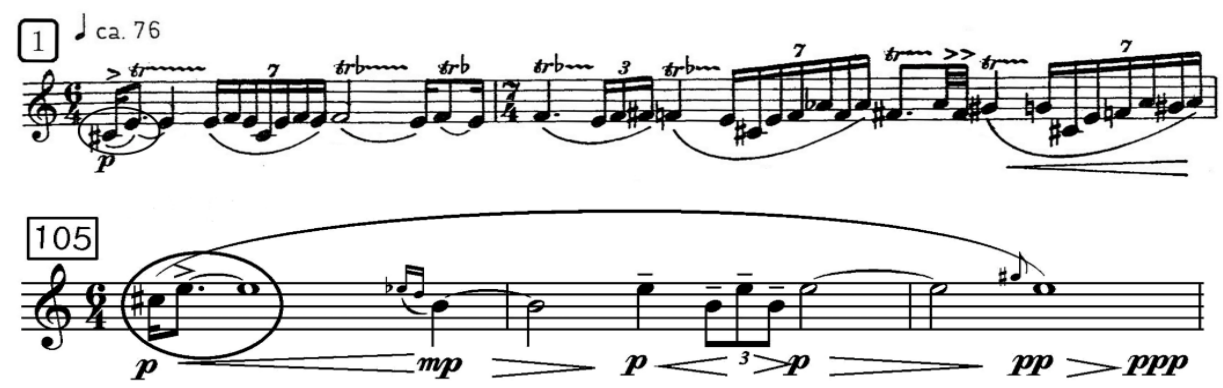


Example 4: Similarities between Section 1 and Section 3
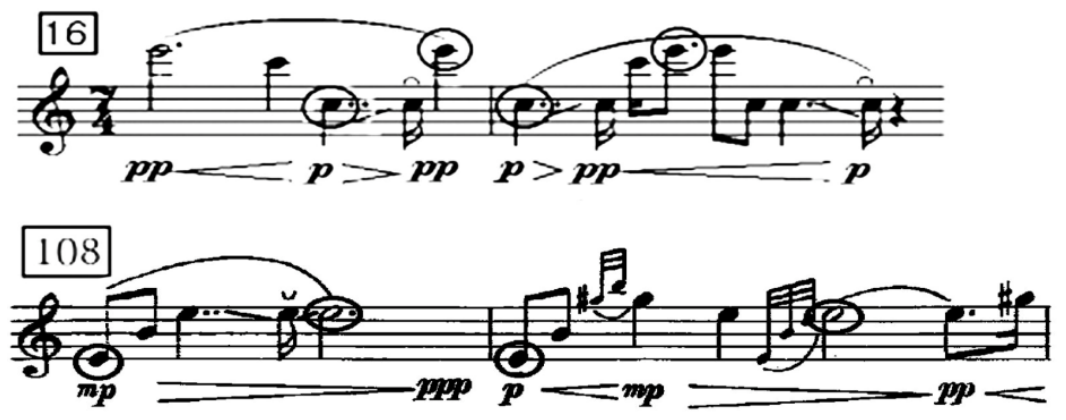

Example 5: Measures 125 and 126

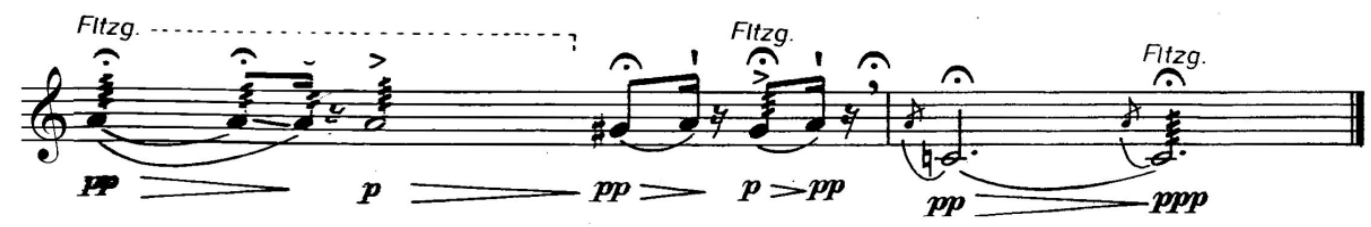

In measure 125, the short A plays after the fermata and creates an effect reminiscent of the daegeum. ${ }^{67}$ In measure 126, the $\mathrm{C}$ sound lengthens with flutter-tonguing before ending. That this piece ends with its final sonority fading into silence invokes the Taoist notion that everything returns to nothingness, which also implies that music is nature, due to this piece's tendency to follow this natural pattern. ${ }^{68}$

\footnotetext{
${ }^{67}$ The daeeum is a Korean traditional bamboo flute.

${ }^{68}$ YoungSun Seo, “A study on traditional compositional techniques of Sori for flute solo (1988) by Isang Yun" (MM thesis, Changwon National University, 2013), 44
} 


\section{Compositional technique}

\section{Main Tone Technique (Haupttontechnik)}

In Yun's work, the main tone technique is an expression from Chinese in which the progress of one sound constantly changes due to the addition of decorative surrounding sounds. The work consists of a single string of sounds, with a single note or sound is at the core, surrounded and decorated by other notes and sounds.

Example 6: Prototype of the main tone technique (Haupttontechnik) from Isang Yun ${ }^{69}$

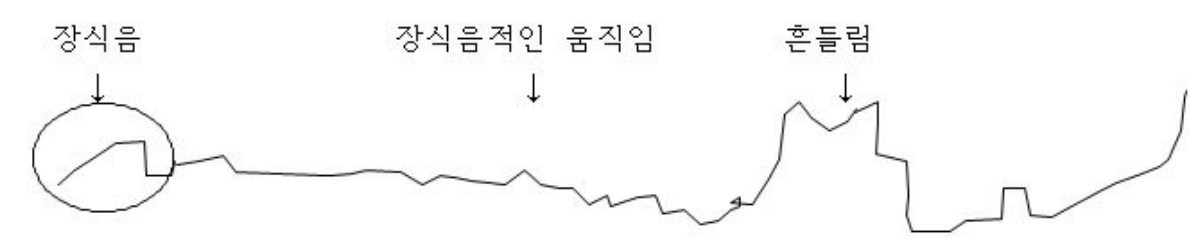

In Yun's Sori, there are no substantial changes in the music, but as it develops, the intervals of teaching pitches around the main tone become larger, as do the changes of ornamentation around the main-tone sound. At the beginning of the work, around measures 1 and 2, Yun emphasizes the main note by decorating it with a trill, as well as with ornaments at its introduction. The main-tone

\footnotetext{
${ }^{69}$ Soojung Kang, “A Study of Etudes for flute solo by Isang Yun” (MM thesis, Catholic University, 2005), 45.
} 
technique is used repeatedly throughout the work, with E being the main tone in the first measure, $\mathrm{F}$ in the second measure, and $\mathrm{A}$ in the third measure, and $\mathrm{B}$ in the fourth measure.

Example 7: Measures 1 to 4

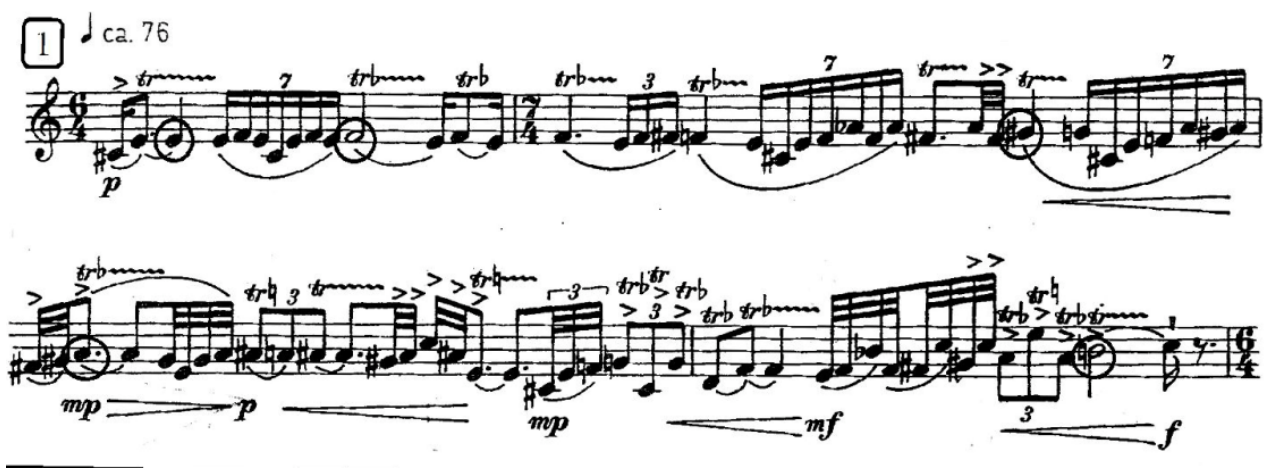

Measures 5 and 6 are slightly looser than any material in the piece up to this time, and changes in accent and melodic motives are frequent. From measure 7 onward, Yun utilizes fewer ornamentations, trills, and tones adjacent to main tone. Rather, the pitches are presented directly and without distraction. Overall, this section displays larger intervals more regularly than material heard previously.

Example 8: Measures 5 to 11

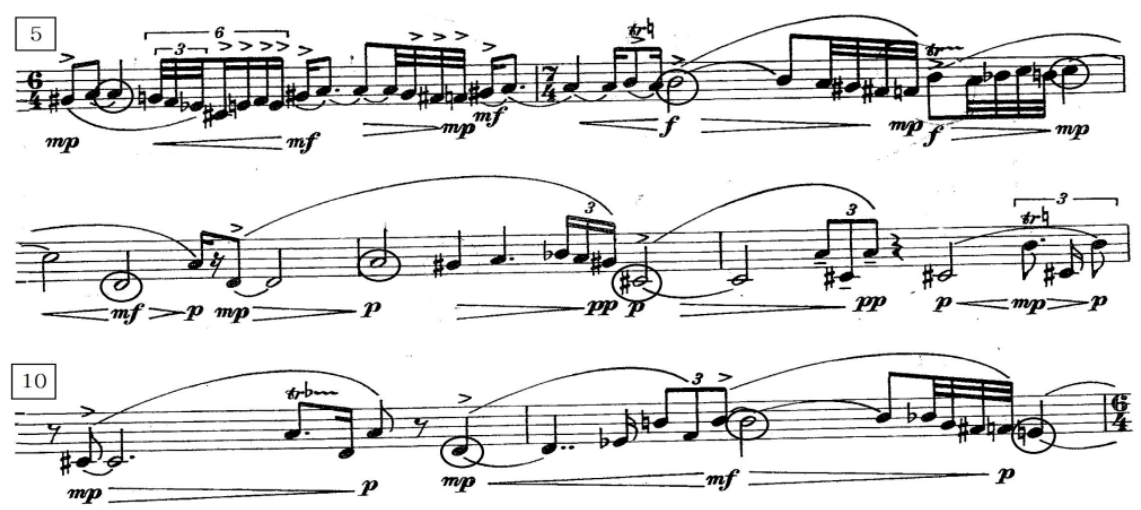


Example 9: A reduction of the main tones in Section 1

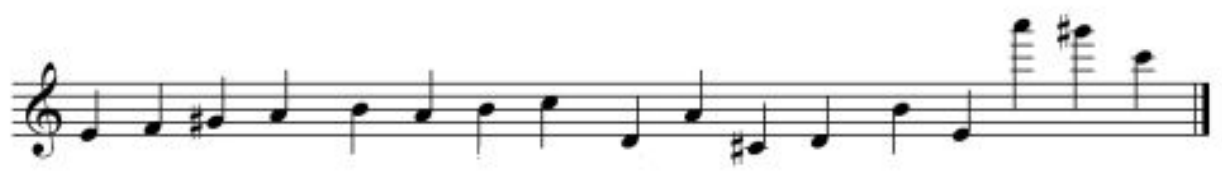

The second section of the work employs the main tone technique through the use of glissandi. The glissandi in this section bend both up and down from the main tone with the goal of drawing attention to the change in pitch. This technique of warping the pitch up and down is called pitch bending. Pitch bending involves deliberately playing the tone high (sharp) or low (flat).

Example 10: Glissandi in measures 16 and 17

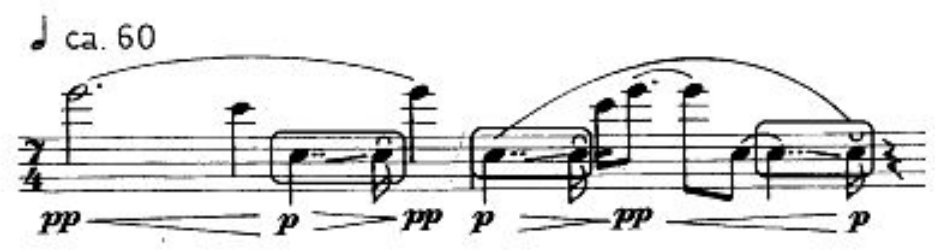

With an open hole instrument, the open hole can be used to create a pitch bending effect. The fingers may be pulled slowly backward or to the side of the desired key in order to uncover the key hole, leaving the finger depressing the rim of the key only and producing a pitch between two genuine notes. For example, a player may achieve a pitch near G\# (though not quite truly G\#) by moving the finger slowly outward. Other special symbols, $1 / 4$ pitch and ${ }^{-}$pitch, are used to represent glissandi by microtones, originally limited to strings, but now also used in wind 
instruments. Flute players must adjust the embouchure according to their physique in order to keep the air stream moving well to achieve this effect. This technique is often used with traditional Korean instruments, such as the daegeum and taepyeongso, ${ }^{70}$ to obtain Korean sound effects.

Example 11: A reduction of the main tones in Section 2

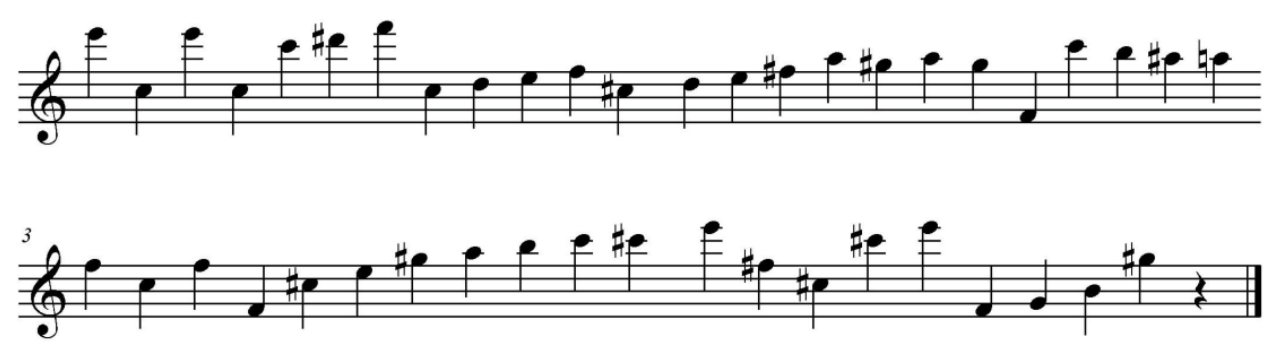

In this section, Yun's music is single-minded: he clings to the goal like an arrow to a target, pushing his power forward.

Example 12: Main tone technique in measures 105 to 107

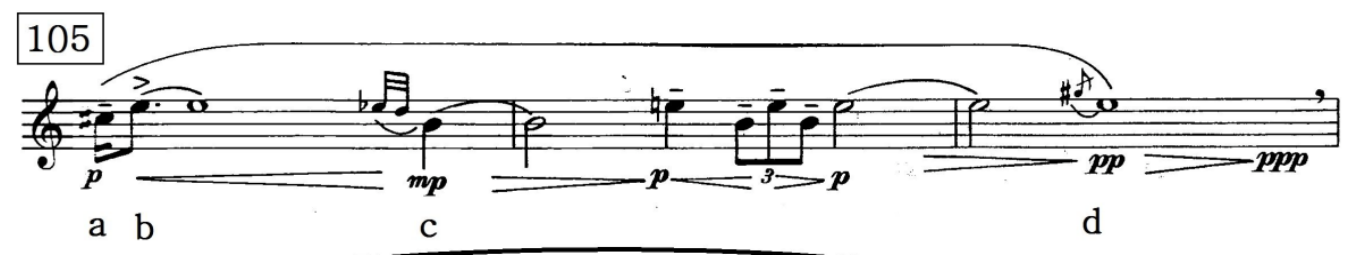

This gesture can be likened to a bowed gesture, which is typically found in the music of Isang Yun as well as traditional Korean music.

70 Taepyeongso is one of the Korean traditional flute. 
A comparable Korean piece is "Cheong Jeong Chaginhanip," breathing effect when the main tone is stretched and shortened, according to the skill of the performer. "Cheong Jeong Chaginhanip" shows more similarity to the main tone technique than any other Korean work: this becomes especially apparent when comparing the main tone technique of Sori in Section 3, measure 105 (Example 12) and the portion of "Cheong Jeong Chaginhanip" (Example 13).

Example 13: Main tone technique of "Cheong Jeong Chaginhanip."

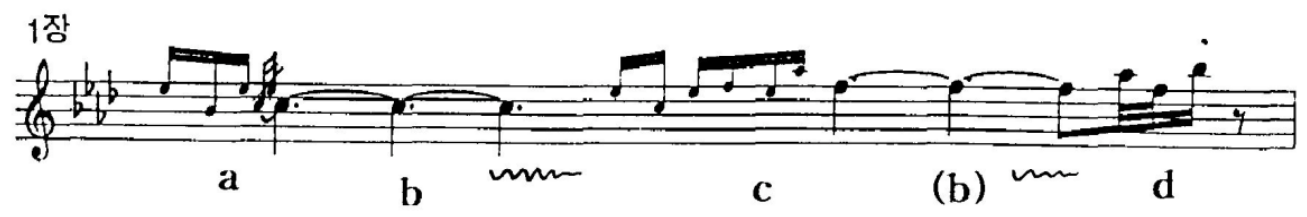

Unlike Sections 1 and 2, the texture of Section 3 lacks ornaments and pitch bends, tending to move directly from one main tone to the next. Additionally, the main tones themselves throughout this section are overall longer in duration. The contrasts throughout this work can be compared to the elements of Yin and Yang, which differ from the oppositional dichotomous aspects of dialectic thought (i.e., the thesis-antithesis-synthesis known from Western philosophy). In short, the contrast between phrases utilizing the main tone technique and those not utilizing it are not in contradiction with each other, but are different aspects of the same.

Example 14 outlines the melodic flow from the beginning of the main tone to its disappearance through A, B, C, D.

71 "Cheong Jeong Chaginhanip" is a Korean traditional folk song. 
Example 14: Measures 73 to $84, \mathrm{~A}, \mathrm{~B}, \mathrm{C}$, and D

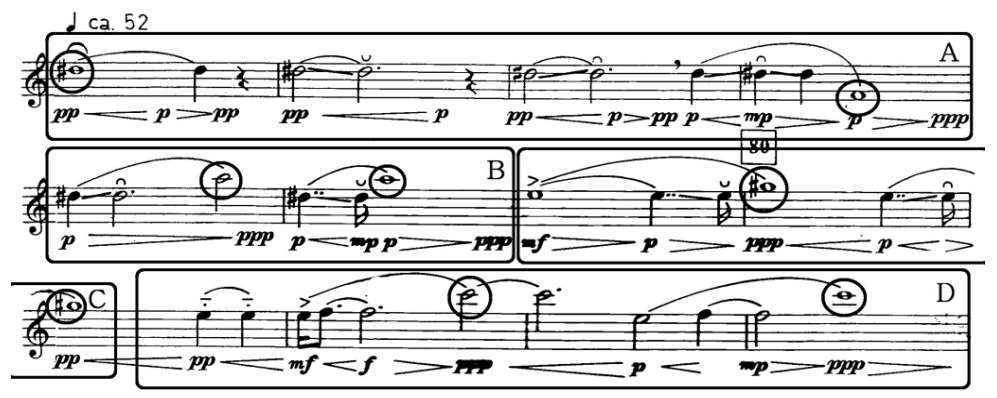

\section{Main Sound Technique (Hauptklangtechnik)}

The influence of main sound technique, a traditional Chinese and Korean compositional technique involving a favoring of minor $2^{\text {nds }}$, minor $3^{\text {rds }}$, perfect $4^{\text {ths }}$, and perfect $5^{\text {ths }}$, is also present throughout Sori. ${ }^{72}$

Sori is a monophonic piece, but it has a harmonic structure in its appoggiaturas and glissandi. The harmony from measures 1 to 6 is formed utilizing only minor 3rds, and measures 7 to 15 are centered on a perfect $4^{\text {th }}$ and perfect $5^{\text {th }}$.

Example 15: Measures 1 to 6

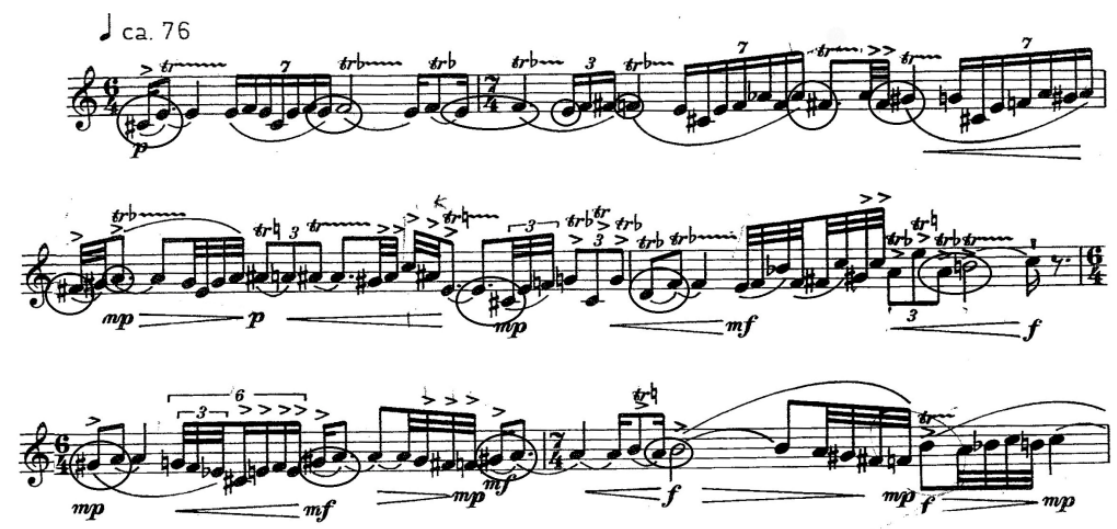

\footnotetext{
${ }^{72}$ KangSeok Jung, “Analysis of Concerto for woodwinds by Isang Yun” (MM thesis, Changwon University, 2004), 20-21.
} 
The main motif of the melody contains pitches that make up minor $2^{\text {nds }}$ and minor $3^{\text {rds }} \cdot{ }^{73}$ It is worthwhile to compare this to the following example: a solo melody from the traditional Korean song, "SeRyeong Mountain," which emphasizes a minor $3^{\text {rd }}$, characteristic of traditional melodies, and includes ornaments at pitch intervals of minor $2^{\text {nd }}$, minor $3^{\text {rd }}$, and perfect $4^{\text {th }}$.

Example 16: Minor $3^{\text {rds }}$ in "SeRyeong Mountain"

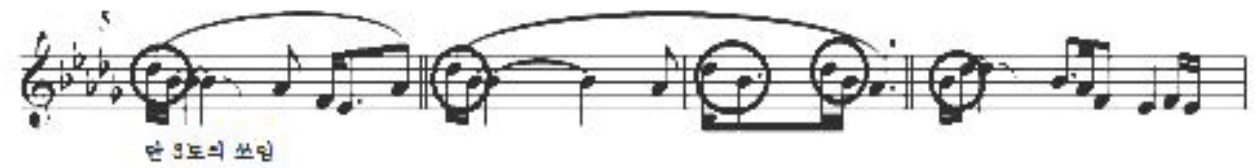

Examples 17: Measures 7 to 15

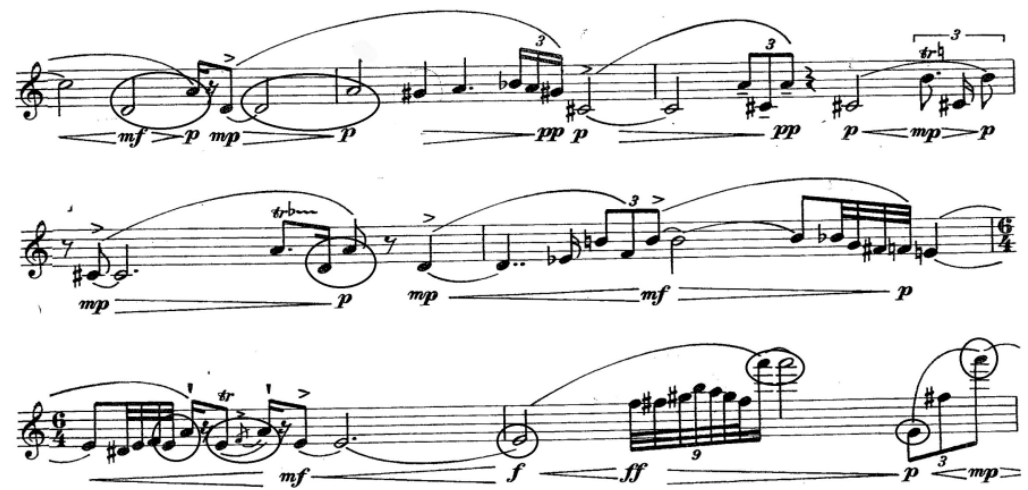

The passage in Example 17 also shows a harmonic profile that highlights a perfect $4^{\text {th }}$ and $5^{\text {th }}$, which have a distinctly East Asian sensibility.

Example 18 features a major $3^{\text {rd }}$ chord, moving around the pitches $\mathrm{C}$ and $\mathrm{E}$. A few excerpts of the chord structure:

\footnotetext{
${ }^{73}$ Sung-man Choi and Eunmi Hong, Isang Yun's history of music life (Seoul: Hangil-sa, 1994), 44.
} 
Example 18: Measures 16 to 18

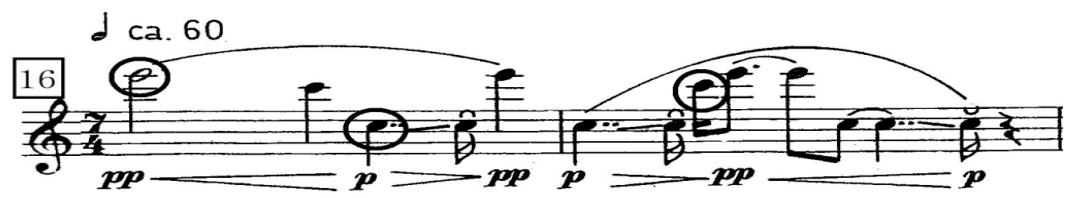

Example 19 demonstrates the structure of major $3^{\text {rd }}$ chords F, A, C\#, E and G\#.

Example 19: Measures 26 to 31

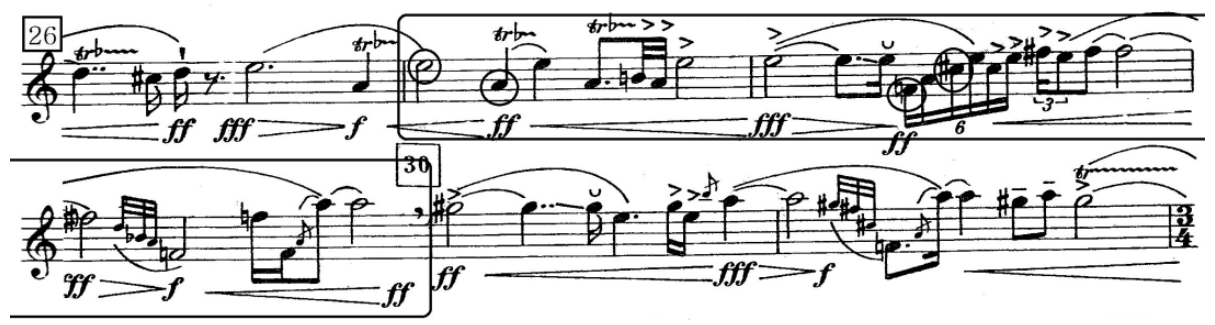

Example 20 demonstrates the structure of major $3^{\text {rd }}$ chords $\mathrm{F}, \mathrm{A}$, and $\mathrm{C}$.

Example 20:Measures 37 to 43

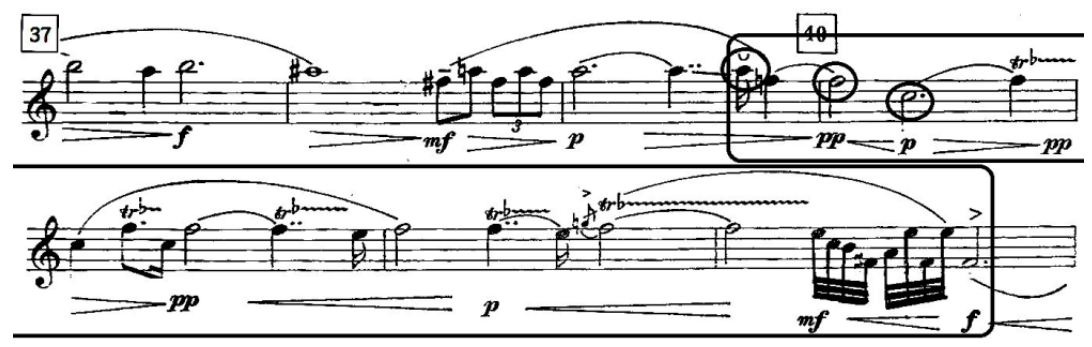


Example 21 demonstrates the structure of major chords F, A, C and minor chords F, Ab, C, and $\mathrm{Eb}$.

Example 21: Measures 32 to 36

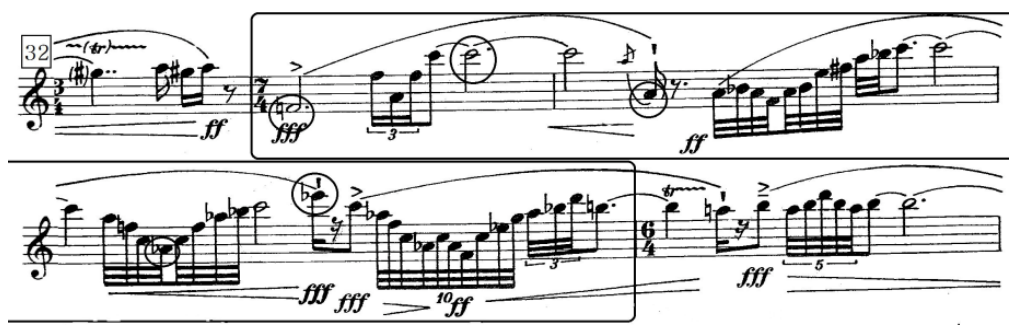

Example 22 demonstrates the structure of minor 3rd chords D, F, and A.

Example 22: Measures 24 to 28

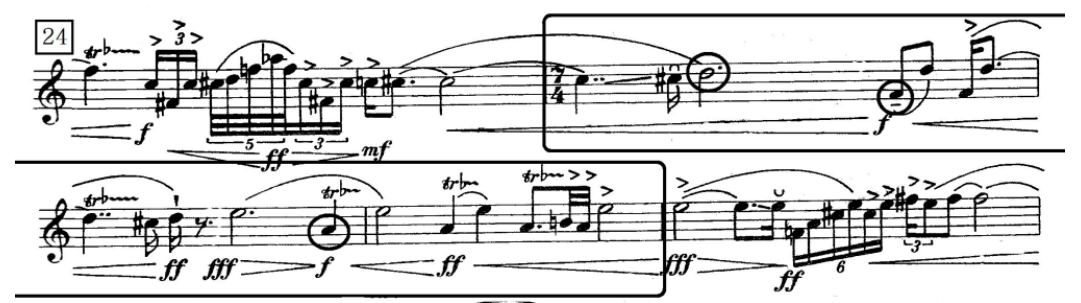

Example 23 demonstrates the structure of diminished $3^{\text {rd }}$ chords $\mathrm{CH}$, E, and G.

Example 23: Measures 47 to 51

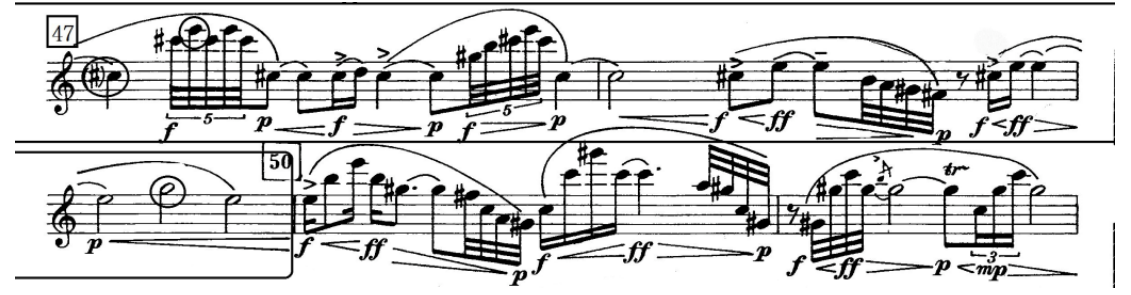




\section{Tone Complex (Tonkomplex)}

Yun also utilizes tone complex, a melismatic flourish consisting of the main note and pitches surround it, throughout Sori. ${ }^{74}$ Example 24 shows a passage that utilizes both grace notes trills in a way that evokes the tone complex. ${ }^{75}$ As seen in Example 24, the main melody is decorated by an appoggiatura before the sounding of the main tone, which is then followed by an agitation of the main tone as achieved by a pitch bend, and a substantial ornamentation before finally arriving at, and concluding on, the ultimate main tone.

Example 24: Bars 108 to $115^{76}$

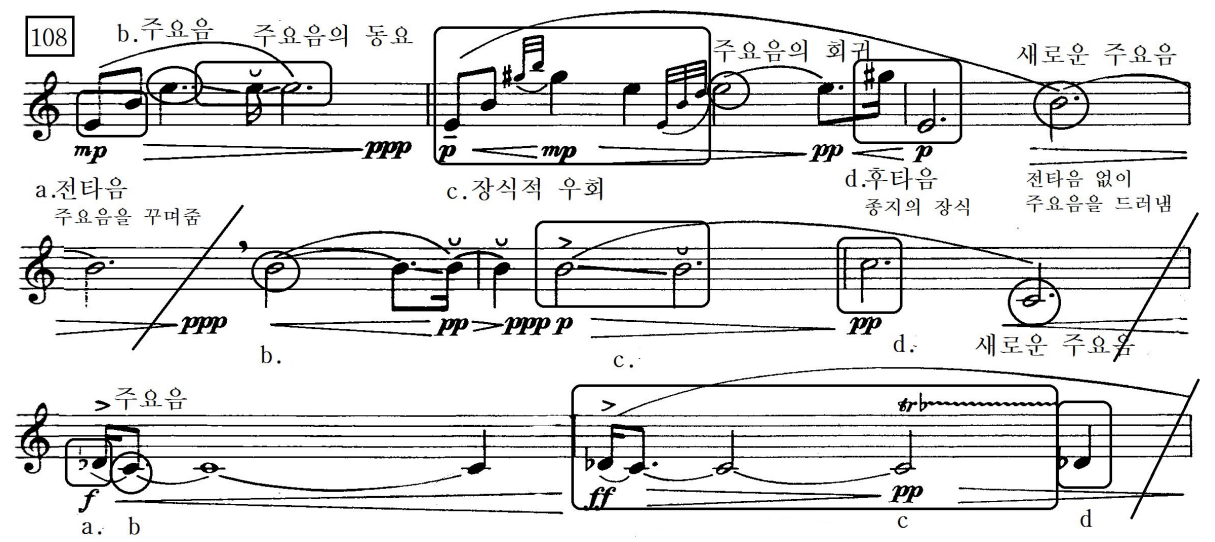

Throughout this piece, the appoggiaturas tend to act as a preparation for the main tone before it sounds. This appoggiatura also has melodic ornamentation, accompanied by several other ornaments and tends to function in pre-tone capacity. It is predominantly ascending and leads to the main tone; in this instance, a boost for the main note would also be appropriate. After this preparation, the main tone rings at one still moment and then flows into the dynamic line. Next,

\footnotetext{
${ }^{74}$ Sung-man Choi and Eunmi Hong, Isang Yun's history of music life (Seoul: Hangil-sa, 1994), 242.

${ }^{75}$ Kang, "A Study of Etudes for flute solo by Isang Yun" (MM thesis, Catholic University, 2005), 59.

${ }^{76}$ Soojung Kang, "A Study of Etudes for flute solo by Isang Yun” (MM thesis, Catholic University, 2005), 61.
} 
the piece engages in a process of changing the sound to one unlike the regular, refined Western aesthetic. Like a continuous change in a winding road, a single note has a long course of sound change. The process of sound change can be transformed through various musical parameters, such as momentary ornamentation of sound, dynamics, glissando, tone color, and vibrato, all of which make it possible to introduce the 20th century's radical playing techniques to the world of sound.

This sound change initially starts with something small, like a light vibrato, dynamic change, tone change, etc. After this soft start, it is likely to grow in intensity so much so that there comes a change from the original note into higher and lower notes. Glissandi with a wide variety of sounds deviate from the first major note, as does large vibrato, and large, decorative detours involving melodies of major and minor tones. This process of evolution and fluctuation of the tone gives each note its own unique value and energy.

The main note eventually returns after undergoing this changing process. The main sound, originating from a single static point, will fluctuate with the dynamic movement, experiencing many bends and large changes due to the continuous flow, then return to the original static point, the main sound. It then forms a small musical phrase accompanied by a single after tone.

\section{Sound Color Composition (Klangfarbenkomposition)}

The following is an example of the compositional technique sound color composition, or the use of ornaments such as accents, trills, and grace notes, as used in Sori, in which there is a 
distinctive bending of the southern sound in "Daegeum Sanjo" 77 and "Jinyangjo."78 Note the comparison between the use of graces notes and the trills as ornamentations.

Example 25: Grace notes and trills as ornamentation in "Jinyangjo"

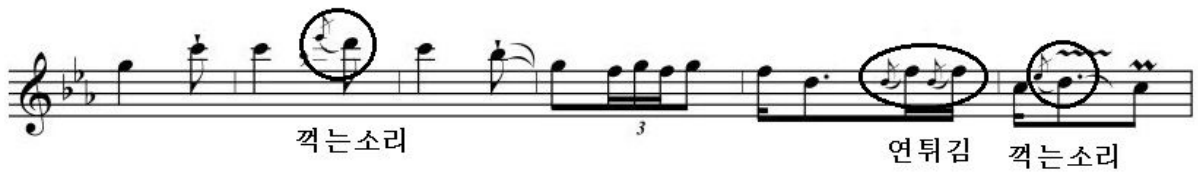

Example 26: Measures 69 and 70 of Sori

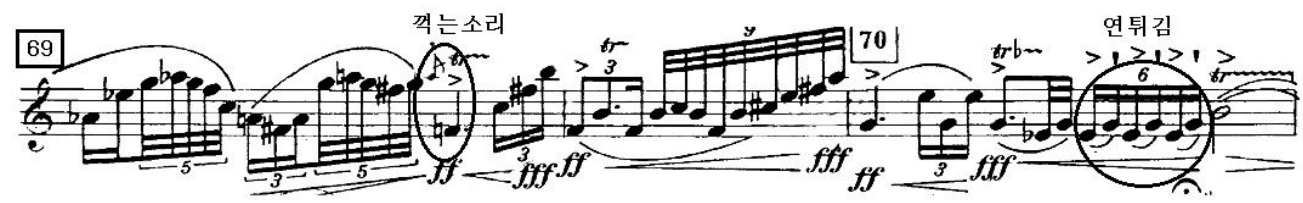

Example 27: Measure 71 of Sori

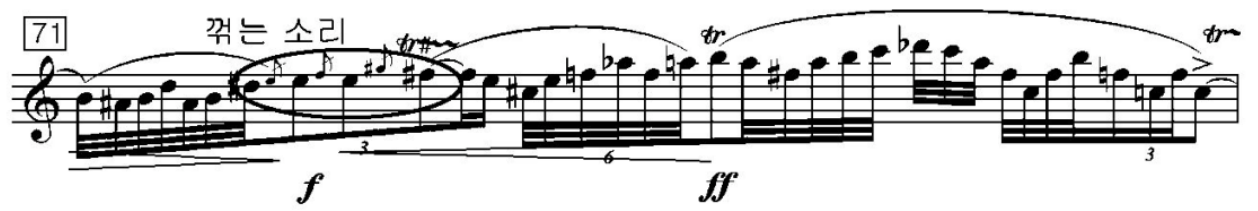

The ornamentations in traditional Korean music tend to unwind over a long period of time and may be quite complex but may end abruptly, and furthermore, may cease at any point throughout the phrase. The most important part of writing a solo piece for the daegeum is including interesting and quick decoration, which Sori employs often.

\footnotetext{
${ }^{77}$ Daegeum sanjo is traditional Korean folk music for the daegeum.

78 Jinyangjo is a traditional Korean folk music.
} 
Example 28: Example of "Cheong Jeong Chaginhanip"

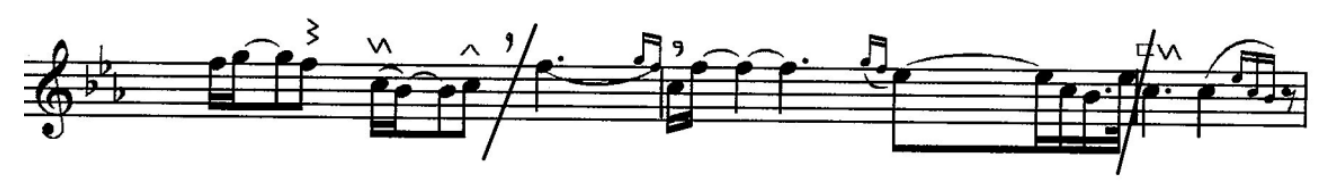

The slash-type symbol of the musical notes indicates a sudden finish after the decorative tone. After this sudden finish, the main tone is played in a connected and sustained manner for a long duration with few decorative tones. Then, another sudden finish occurs, followed by the main tone again.

Example 29: Measure 55

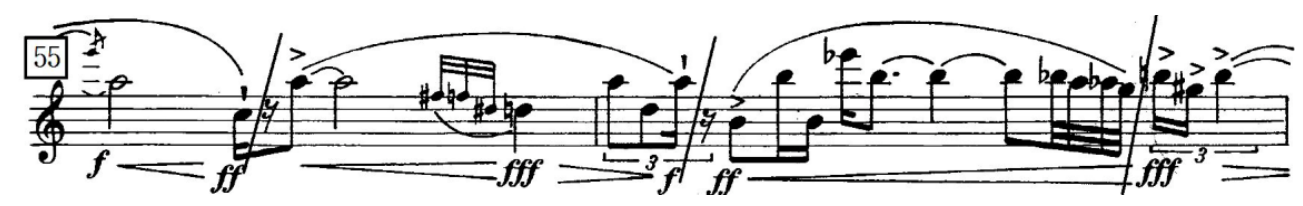

Measure 55 shows the sudden finish after the decorative tone, as occurs during "Cheong Jeong Chaginhanip" in Example 28. In this instance, it is necessary to breathe and produce the sound aggressively and abruptly in order to interrupt the air stream and stop the sound. 
Playing Around (Umspielung)

This section will examine Yun' use of "playing around," a technique in which the ornaments discussed thus far are utilized specifically to pulsate a tone and give the music an intense energy. ${ }^{79}$

Example 30 features glissandi, pronounced trills, vibrato, and pitch bends, as well as a broadly divided spectrum of tone changes. These elements are utilized to give a sense of vitality and life to the passage.

Example 30: Measures 16 to 20 of Sori

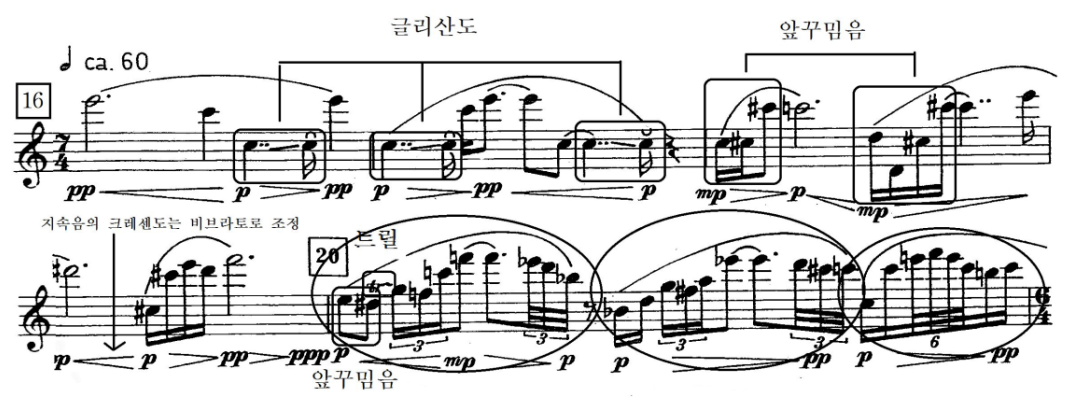

\section{Korean Musical Elements}

Isang Yun recreates the distinct tone of Korean instruments through Western instruments. When transliterating, the oboe a substitute for the Korean piri flute, the harp is a gayageum, ${ }^{80}$ the flute is a substitute for the daegeum, the violin is a substitute for the haegeum, ${ }^{81}$ and the brass instruments have the same effect as the hun and nagak. ${ }^{82}$ Yun extended his range of special techniques to these traditional Western instruments by utilizing the distinctive playing styles of

\footnotetext{
${ }^{79}$ Sung-man Choi and Eunmi Hong, Isang Yun's history of music life (Seoul: Hangil-sa, 1994), 348.

${ }^{80}$ Gayageum is a traditional Korean string instrument, similar to a harp in Western music.

81 Haegeum is a traditional Korean string instrument, similar to a violin in Western music.

${ }^{82}$ Hun and nagak is a traditional Korean brass instrument.
} 
Korean musical instruments on Western ones. This contributed to the formation of his unique tone composition method, in addition to the composition technique of changing the individual sound that was his "original musical language." Sori is an example of a work by Yun that draws inspiration from Korean instrumental methods as performed on Western instruments. ${ }^{83}$

One traditional Korean technique Yun capitalizes upon in his works is knowns as sigimsae. Sigimsae refers to a decorative tone or a short-length sound that acts as an embellishment in front of or behind a skeletal note. In broad terms, sigimsae includes expressive functions given to any sound to help promoted natural connection and flexible flow. It is also called sikeom, meaning it has an important role regarding vitality of sound. Sigimsae appears in slightly different forms depending on the musical instruments, as it has a deep relationship with the instrument's original laws. It appears in both contemporary music and folk music: with contemporary music, the sound is narrowed down, while folk music has a more dramatic style. However, sigimsae is most widely used in East Asian folk music, where the performers are required to be capable and flexible. Accordingly, sigimsae serves as a benchmark to judge musicians' performances. ${ }^{84}$

Sigimsae had a profound effect on Yun's main sound method. Addressing sigimsae, Yun wrote, "The natural transformation of all sounds is understood as a decorative function and a part of the same sound, rather than being understood as a pitch that forms a melody from the viewpoint of the tone. ${ }^{\prime 85}$ Korean composer Seok-hee Kang (b. 1934) ${ }^{86}$ also used sigimsae in his work, characterizing as "vibration, trembling, noise after sounding, deriving of harmonics through dugout, barrel, accumulation of sound and subsequent reverberation., ${ }^{, 7}$

\footnotetext{
${ }^{83}$ Soojung Kang, "A Study of Etudes for flute solo by Isang Yun” (Master's thesis, Catholic University, 2005), 1617.

${ }^{84}$ Seo Han Beom, ed. A Study of Korean Traditional Folk Music (Seoul: TeaRim Sa, 2009), 240-241.

${ }^{85}$ Sung-man Choi and Eunmi Hong, Isang Yun's history of music life (Seoul: Hangil-sa, 1994), 240.

${ }^{86}$ Seok-hee Kang (b.1934) is a Korean composer and professor.

${ }^{87}$ Choi and Hong, Isang Yun's history of music life (Seoul: Hangil-sa, 1994), 240.
} 
Another traditional Korean technique is nonghyun. Nonghyun is a term used for string instruments, while yosung is used for wind instruments and vocal music. The basic meaning of nonghyun and yosung is the same: nonghyun is a left-handed method used to pluck string instruments, such as a geomungo ${ }^{88}$ and a gayageum, and both it and yosung refers to the vibration of the sound as if it is "shaking." The sound can be either wind or vocal music, and this effect can be compared to the vibrato and tremolo in Western music. ${ }^{89}$

Example 31 demonstrates different forms of yosung. Vibrato is used in conjunction with, and in support of, the dynamics indicated throughout this phrase. To invoke this sonority, intense vibrato would be used on the pitches marked $f f$, which supports the notion of intense wind and air. After this explosion of intensity, the vibrato should relax and decrease in energy as the dynamic fades. In this music, it is necessary to make sure the main sound is heard correctly and distinguished from other ornaments. $^{90}$

Example 31: Measures 44 to 48 of Sori $^{91}$

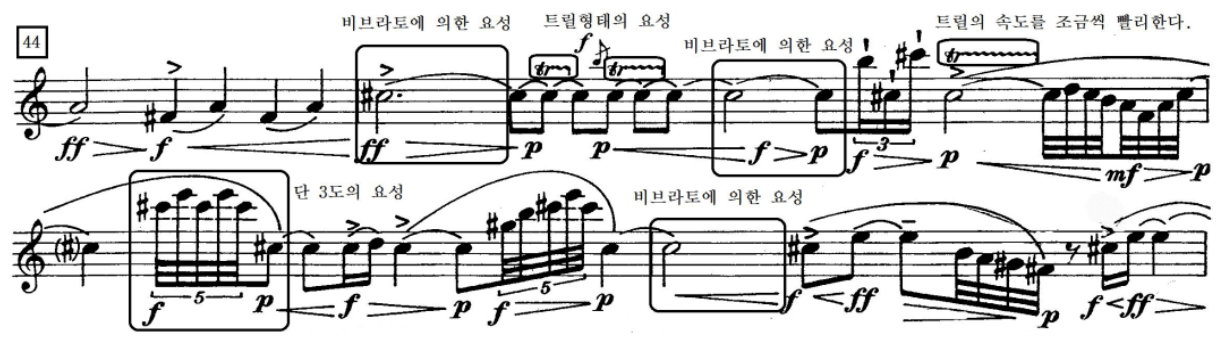

\footnotetext{
${ }^{88}$ Geomungo is a Korean traditional string instrument.

${ }^{89}$ Seo Han Beom, ed. A Study of Korean Traditional Folk Music (Seoul: TeaRim Sa, 2009), 245.

${ }^{90}$ Soojung Kang, "A Study of Etudes for flute solo by Isang Yun” (Master's thesis, Catholic University, 2005), 2932.

${ }^{91}$ Kang, “A Study of Etudes for flute solo by Isang Yun” (Master’s thesis, Catholic University, 2005$), 67$.
} 
Yosung in Korean music is often compared with the Western trill in terms of tempo; but while the Western trill is tremble in constant tempo, the Korean yosung depends on the flexibility and skill of the performer.

In Example 32, the pitches before and after the trill are absorbed by it and this entire segment is played as one idea. The last note should reverberate into the silence, and this will be achieved by ending the phrase with a forte dynamic and intense (fast and wide) vibrato. An abrupt ending of the final pitch will produce a ringing echo.

Example 32: Measures 30 to 32 of Sori $^{92}$

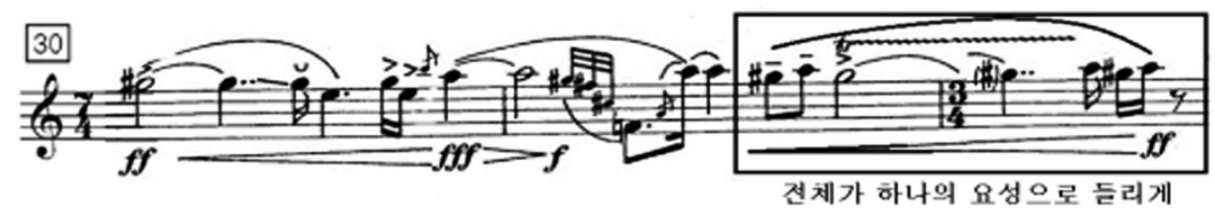

Another traditional Korean technique that makes an appearance in Yun's Sori is knowns as Chuseong. Chuseong means "push up the end of the sound" or "lift up the end of the sound." This is the effect triggered by moving from bass to treble, when the bass is accented or emphasized to create a forward energy the results in the treble's growth; it is somewhat similar to the Western "appoggiatura." The initial pitch sounds on a lower sonority which is then followed by the next pitch which is typically a $2^{\text {nd }}$ or $3^{\text {rd }}$ up from the bass. In addition to this change in tessitura, the performer is expected to "push the sound up" by increasing the intensity of the air stream or even accenting the arrival tone. ${ }^{93}$

\footnotetext{
92 Soojung Kang, “A Study of Etudes for flute solo by Isang Yun” (Master's thesis, Catholic University, 2005$), 69$.

${ }^{93}$ Kang, "A Study of Etudes for flute solo by Isang Yun” (Master's thesis, Catholic University, 2005), 25-30.
} 
Example 33: Measures 1 to 4 of Sori

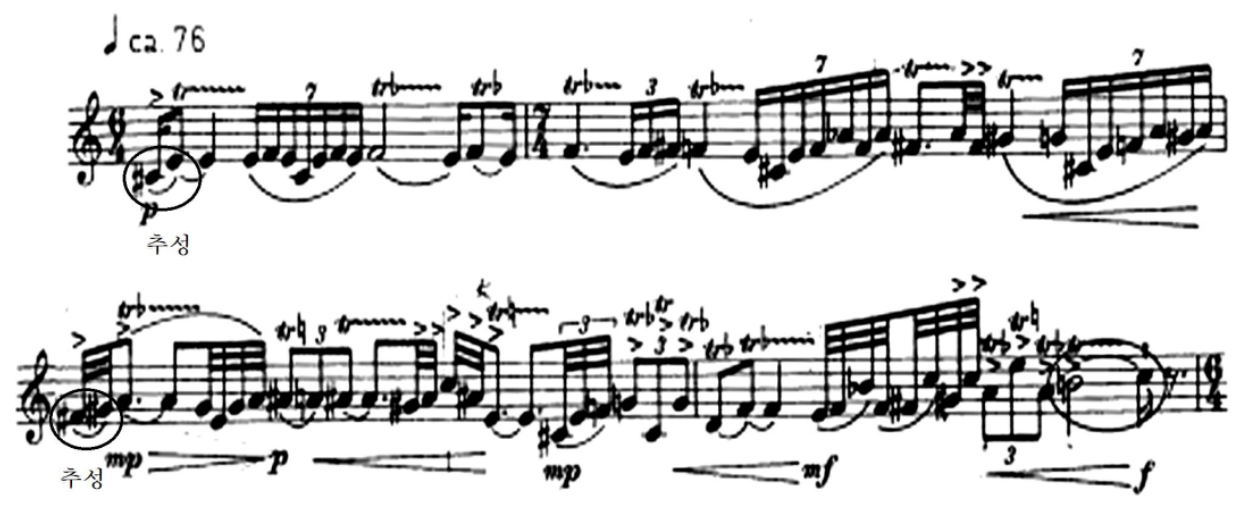

In measures 1 and 2, there is a jump from $\mathrm{C} \#$ to $\mathrm{E}$ followed by movement from $\mathrm{F} \#$ to $\mathrm{G} \#$ in measure

3.

Tieseong, another traditional method used by Yun, is the direct opposite of the aforementioned chuseong. Tiesong is often chromatic and is a phrase or gesture that lowers the tessitura, moving from a higher pitch initially to a lower pitch ultimately. ${ }^{94}$ Example 34 below shows this.

Example 34: Measures 5 to 9 of Sori

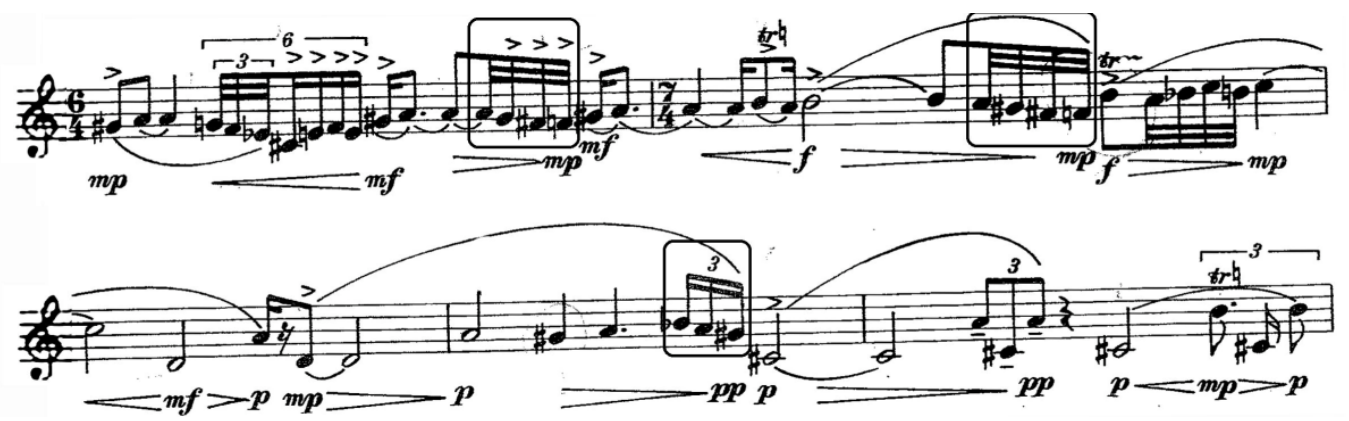

\footnotetext{
${ }^{94}$ Soojung Kang, “A Study of Etudes for flute solo by Isang Yun” (Master's thesis, Catholic University, 2005$), 31$.
} 
The final traditional Korean technique used by Yun in this work is junsung. Junsung means to "roll the sound." It is similar to the Western practice of a "turn." This energetic ornamentation is often comprised of many notes of short duration (sixteenth notes, thirty-second notes, etc.) and is often found immediately prior to chuseong and a sustained pitch. Example 38 junsung. The main sound in this piece is not limited, and can be made longer and shorter in different ways, depending on the intention of the composer and the performer.

Example 35: Measures 12 to 15 of Sori

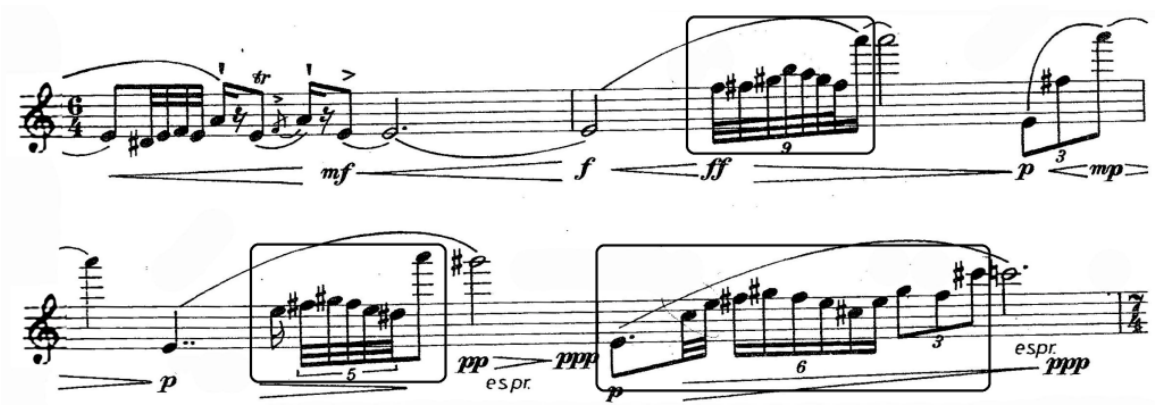




\section{Chapter 5}

Analyses of Other Works for Solo Flute and Selected Chamber Works by Isang Yun

Among Isang Yun's works are several pieces for solo flute, a flute concerto, and chamber works including one or more flutes. Yun described the flute as a Western instrument capable of producing a highly flexible sound, with the quality of its tone ranging from a very full, resonant sound to a small, pristine sound to an aggressive, rough round. ${ }^{95}$

Yun's works including flute in the instrumentation often evoke the sound of traditional Korean instruments, such as the daegeum and Korean piri flute, in order to communicate particular Korean musical idioms for the flute. The previous chapter explored how Sori contains musical adaptations of ideas borrowed from Eastern philosophy; this chapter will explore and analyze other flute solo works and chamber works by Yun, to demonstrate how these philosophical concepts are used in comparison with Sori. Particular focus will be placed on investigating the similarities and differences between Sori and Yun's Etudes for flute solo, Garak for flute and piano, Concerto for flute and small orchestra, and his Flute Quartet. The following analyses will reference back to the analyses of Sori in the previous chapter.

\footnotetext{
${ }^{95}$ Jearyeong Na, “A Study of Isang Yun's selected flute pieces” (DMA dissertation, Seoul National University, 2015), 19
} 


\section{Analysis of Etudes for Solo Flute}

Etudes for solo flute was dedicated to Gunter Freudenberg (1923-2000) ${ }^{96}$ and Ursula Freudenberg ${ }^{97}$ in 1974. Professor Chang-kook Kim (b. 1942) ${ }^{98}$ performed the first movement of the work in Kyoto, Japan on July 18, 1974, and Beate Gabriela Schmidt (b. 1949) ${ }^{99}$ performed it in Berlin, Germany on November 3 of the same year.

While composing this work, Isang Yun developed several new techniques, particularly fingering techniques, while reviewing performance challenges with the flutist Schmidt. Yun's techniques influenced modern composers and performers by expressing both modern extended flute techniques and performance practices as well as incorporating elements of traditional Korean music. $^{100}$

This work consists of five etudes, each with its own unique aesthetic. The individual character of each etude is achieved through several extended techniques meant to serve as an exercise in mimicking the sound of traditional Korean music, though they are performed on traditional Western musical instruments. The Etudes call for four differently sized flutes. Example 36 is played with the flute in the beginning of the first piece, "Moderato." The main sound technique is well-known: the restrained ornaments and the sustained notes are kept tense, and the finished sound form is reminiscent of the daegeum.

\footnotetext{
${ }^{96}$ Gunter Freudenberg (1923-2000) was a German philosopher and professor.

${ }^{97}$ Ursula Freudenberg was the wife of Gunter Freudenberg.

${ }^{98}$ Chang-kook Kim (b. 1942) is a Korean flutist and professor.

${ }^{99}$ Beate Gabriela Schmidt (b. 1949) is a German flutist.

${ }^{100}$ Yong Whan Kim, Research on Isang Yun (Seoul: SiGonSa, 2001), 53-55.
} 
Example 36: Etude for solo flute No. 1 Moderato, measures 1 to 4 of introduction

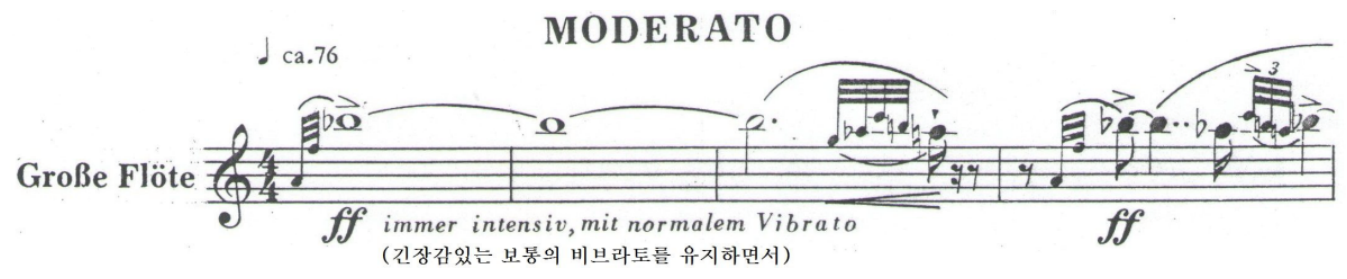

"Adagio" is the second Etude. As see in Example 37, this piece is the slowest of the five etudes, beginning quietly with the low and dark tones of the alto flute. Throughout this number, only a few different pitches are utilized. However, an array of characters and atmospheres are achieved as the performer exploits many different tone colors. These changes in tone color are produced by altering the air speed from slow to fast, changing the air pressure, and adjusting the embouchure. This etude is a well-documented demonstration of "stillness in motion," as it changes only the dynamics and vibrato in a single fixed pitch.

Example 37: Etude for solo flute No. 2.Adagio, measures 1 to 7 of introduction

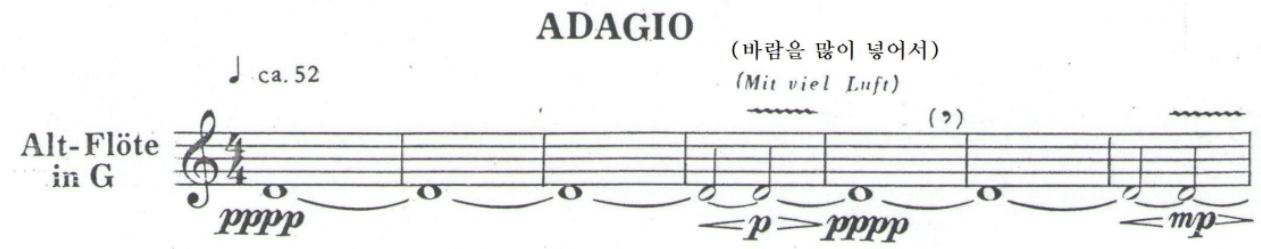


"Allegro" is the third of the Etudes. As shown in Example 38, the piece is written for the piccolo. It emphasizes the colorful and unique tone of this instrument, and changes into a lively form as the long and melodic sounds are repeated. The traditional Korean musical technique that inspired this movement is junsung, the flourish-like turn that "rolls the sound." this may be seen on beat two of measure two in Example 38. Additionally, the East Asian philosophy of "stillness in motion" is present throughout this etude. "Stillness" is achieved through the use of long, sustained tones (as seen in measure one in the following example), and motion within this stillness is achieved through the use of trills, tremolos, and dynamic change. ${ }^{101}$

Example 38: 3. Allegro, measures 1 and 2 of introduction.

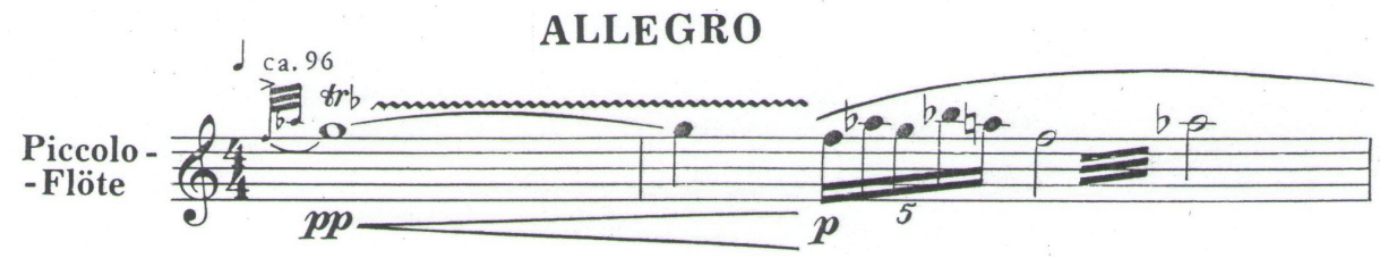

The fourth etude, "Andante," is played on the bass flute. The tempo of this work is quite slow, with one beat per second, and serves as a contrast to the previous etude (played on piccolo). There is not much movement during the whole piece, and one tone is used for most of the work, and a glissando is used to a timbre and pitch . The bass flute is meant to be played with a hollow, flat sound quality that invokes a sense of stillness and emptiness. This approach is significant because it shows Yun's incorporation of the third element of Taoism. Here, the bass flute is representing the "nothingness" that everything returns to repeatedly throughout the cycle that makes up eternity.

\footnotetext{
${ }^{101}$ Jearyeong Na, “A Study of Isang Yun's selected flute pieces” (DMA dissertation, Seoul National University, 2015), 27
} 
However, just as in Taoism, the "nothingness" does not truly cease to exist, but is still constant, evoking eternity.

Example 39: 4. Andante, measures 1 to 4 of introduction.

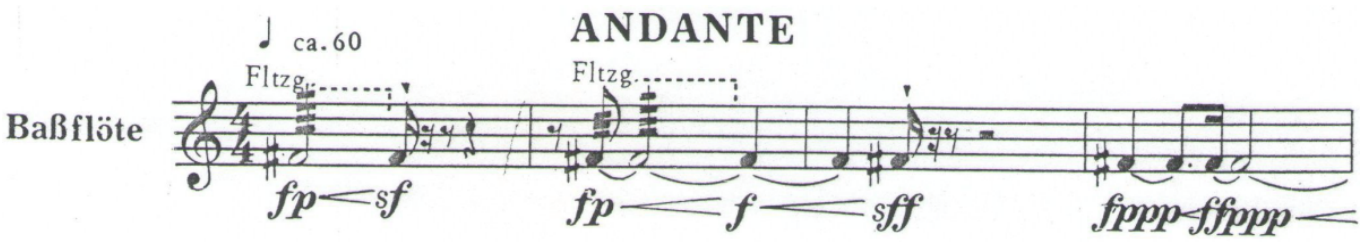

The final Etude, as seen in Example 40, is performed, again, on $\mathrm{C}$ flute. It begins with a main tone that quickly gives way to a junsung-like flourish on the third beat of measure two. This is again followed by a sustained main tone and then ultimately a much more dramatic flourish. This toggling of stagnant, grounded energy on the sustained pitches as juxtaposed with the intensity of the flourishes shows Yun's incorporation of Yin and Yang into his music.

Example 40: 5. Allegretto, Introduction Section.

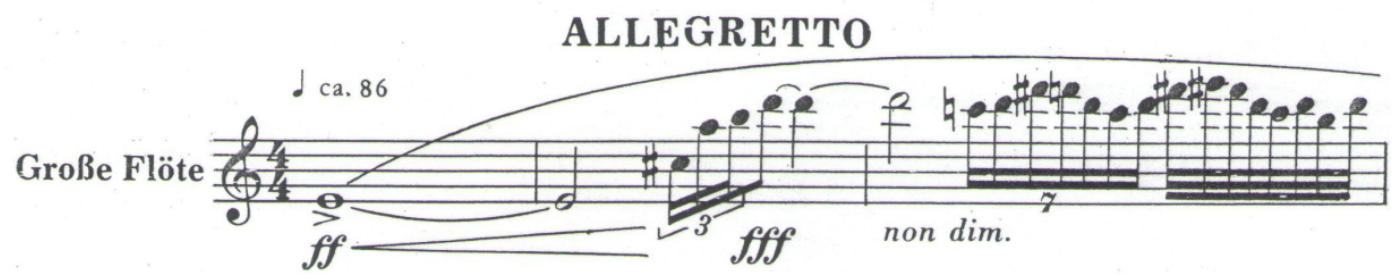

Each of the five Etudes features either flute, alto flute, piccolo or bass flute. Therefore, to play this piece, the performer needs to be competent on all four flutes differently and have strong technique, as well as the ability to produce many modern expressions, flexibility of the embouchure that goes beyond three octaves, and the ability to sustain notes and phrases for a long 
duration. This piece is one of Yun's most popular flute works for demonstrating extended techniques.

\section{Analysis of Garak for Flute and Piano}

Garak was composed in 1963 and premiered in Berlin on September 11, 1964, with a performance by Karl Heinz Zoller (1928-2005). Garak is composed as a two-part musical volume, with Gasa for violin and piano (1963) and Gagok (1972). During the period between the 1960s and early 1970s, Isang Yun wrote several pieces expressing his feelings about East Asia, including his orchestral work Bara (1960), Loyang for chamber ensemble (1962), his opera Ein Schmetterlingstaum (1968), among others.

Yun lived in Freiburg around 1960, where he was invited to lecture on various radio stations about Chinese and Korean court music. Having a strong personal interest in East Asian culture, Yun studied music and read books on the topic. He composed Gasa and Garak at this time, both of which were inspired by Chinese non-court music and the religious music of temples. Both works give a grand and glamorous impression of East Asian culture, often due to the inclusion of a long and sustained sound. Garak has a single movement, divided into three parts according to the composer's tempo indications. ${ }^{102}$

Example 41 is a slow and static passage in which the change gradually appears around the continuous sound. Example 42 shows fast movement and dynamic energy. In Example 43, the tempo is slow and the piece achieves a stable, grounded atmosphere through sustained

\footnotetext{
102 Jearyeong Na, “A Study of Isang Yun's selected flute pieces” (DMA dissertation, Seoul National University, 2015), 21-24.
} 
pitches and few moving notes, and the final section disappears through the endless continuous sound (invoking eternity as understood in Taoism).

Example 41: Garak for flute and piano, beginning

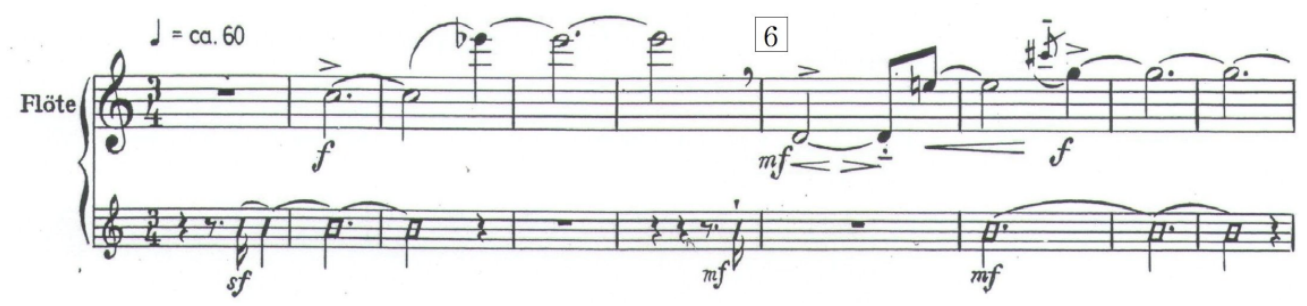

Example 42: Garak for flute and piano, measures 73 and 74

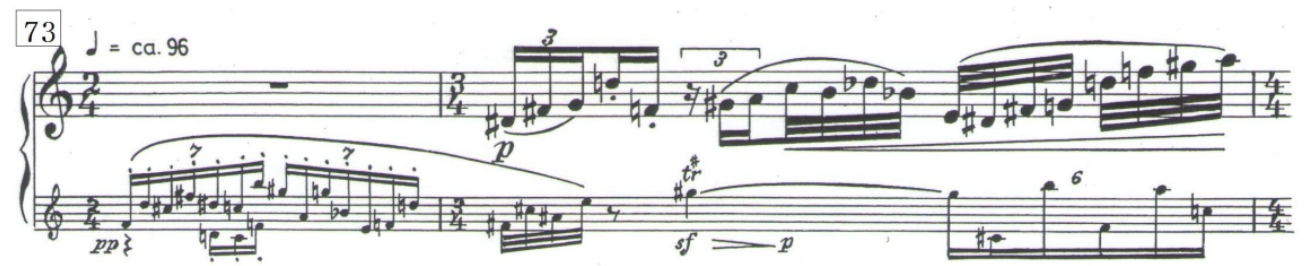

Example 43: Garak for flute and piano, measures 122 and 123, measures 167 and 168
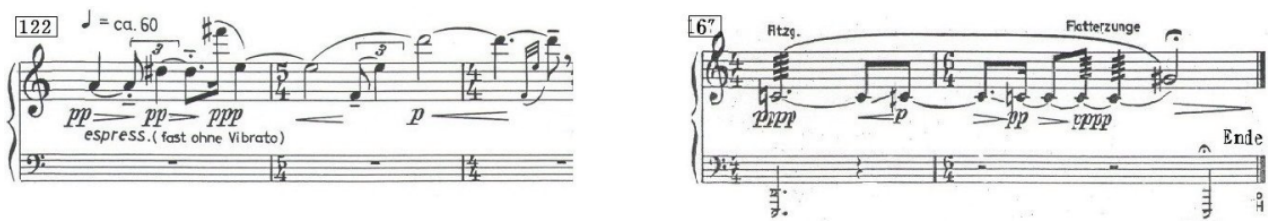

In Garak, the melody has a notable rhythmic pattern, especially in the dynamic middle part. Yun, in his preface to the work, wrote that "Garak is a special rhythm, which flows by a melody and is 
accompanied by a certain expressiveness." ${ }^{103}$ This melody is interpreted as bearing clear relation to the rhythms of traditional Korean music.

In the fluid and constantly-changing ending of the work, the influence of "stillness in motion" becomes apparent. It can be compared to Debussy's tendency to pursue constant change and formal openness in favor of the three-part compositional format. Yun was also influenced while composing this piece by Schoenberg 's twelve-tone scale: he made a matrix of each work, arranging it in various ways. ${ }^{104}$ However, it was only a skeleton framework, and when he imagined different acoustics, he let them flow freely, using the piano and solo instruments to present the musical ideas in various forms.

This piece is also an experiment in main tone technique in that the work is developed around a certain central sound. In this sense, Garak for flute and piano is a transitional work that can be regarded as an important piece from the 1960s.

\section{Analysis of Concerto for Flute and Small Orchestra}

This work was commissioned by the Musicktage Hitzacker in Germany, and was premiered in 1977 by flutist Karl Heinz Zoller, a principal of the Berlin Philharmonic. Yun composed thirteen instrumental Concertos, from the cello Concerto composed in 1975-1976 to three violin Concertos in 1992. In the 1960s, he composed works with Korean titles, while from the late 1970s onwards he transitioned to traditional European music genres, with Western musical titles and forms such as concertos, symphonies, and preludes. His change in perspective also led to him putting human

\footnotetext{
${ }^{103}$ Jearyeong Na, “A Study of Isang Yun's selected flute pieces” (DMA dissertation, Seoul National University, 2015), 23.

${ }^{104} \mathrm{Na}$, “A Study of Isang Yun's selected flute pieces" (DMA dissertation, Seoul National University, 2015), 27.
} 
figures in his works, and he expanded his musical appreciation to a more generalized "public" one. $^{105}$

The motif of this Concerto is relatable and universal, expressing a message of world peace and love for humanity. The musical structure of the work is centered predominantly on the interval of a minor third and favors consonant intervals throughout. This use of the interval invokes the main sound technique.

Yun compared the concerto genre with his experiences in East Berlin, specifically having two mutually opposing musical instruments arranged as solo instruments and orchestra. Dialogue with the environment and between two groups that cannot be reconciled is a central part of Yun's Concertos. "After the mid-seventies," Yun said, "I decided to write a series of instrumental concertos. To do this, I needed a musical language with humanity". ${ }^{106}$ This clearly highlights the influences of humanism in his works, specifically his concerti.

By incorporating legends and fairy tales into this Concerto, Yun portrayed his experiences of standing on the borderline between life and death and capturing the pain of the division of the North and South in his country. The work expresses the continued internal conflict of Korean citizens who hope for unification of the motherland, a theme commonly present in Korean literature.

Yun commented on this Concerto: "Music starts from nothingness and goes back to nothing". ${ }^{107}$ Starting from nothingness, a storyline is created by the solo line as played on alto flute: in the natural surroundings of beautiful temples, a man's blood and flesh tangle together in passion, meditation, duties, and human conflicts and counsels. Meanwhile, the orchestra unfolds

\footnotetext{
105 Jearyeong Na, “A Study of Isang Yun's selected flute pieces” (DMA dissertation, Seoul National University, 2015), 35-40.

${ }^{106} \mathrm{Na}$, “A Study of Isang Yun's selected flute pieces" (DMA dissertation, Seoul National University, 2015), 50-55.

${ }^{107} \mathrm{Na}$, “A Study of Isang Yun's selected flute pieces” (DMA dissertation, Seoul National University, 2015 ), 52.
} 
the mysterious night scenery. The solo reaches its climax as it begins the cadenza. This cadenza, performed on $\mathrm{C}$ flute, liberates itself and leads to the climax in this piece: in the process of returning to reality, it changes back to the alto flute from the beginning, and thus music returns to nothingness through meditation. ${ }^{108}$ According to Yun's commentary on the work, the solo is likened to a human, based on the contents of the legend. The orchestra represents the environment, destiny, or nature, expressing the conflicts between two musical instruments and creating a reversed part.

The overall bell-curve shape of the narrative, and the move from the more grounded, hollow-toned alto flute to the $\mathrm{C}$ flute and back again, invoking the third element of Taoism, eternity. The juxtaposition of the $\mathrm{C}$ flute and alto flute also show the influences of Yin and Yang, with the alto flute (lower tessitura, deeper, darker tone, etc.) acting as Yin and the $\mathrm{C}$ flute (higher tessitura, brighter and more energetic tone) acting as Yang.

This work is a single-movement concerto, and can be divided into three parts: slow-fastslow, as the tempo changes. The first section (at the beginning of Example 44) is in a slow 4/4 meter and utilizes a dancing rhythm that repeats with eighth notes, starting with the alto flute as part of the orchestra (Measures 1 to 103 ). The alto flute gives way to the $\mathrm{C}$ flute in measure 83 . Next, the second section begins with a meditative character, as seen in Example 45 (measures 104143), as the flute monologue is supported by a transparent orchestral accompaniment (measures 144-171). Finally, the third section occupies measures 172-302; in Example 46, a brilliant dance is followed by the flute cadenza section of measure 246 .

\footnotetext{
108 Jearyeong Na, “A Study of Isang Yun's selected flute pieces” (DMA dissertation, Seoul National University, 2015), 55 .
} 
Example 44: Flute Concerto and Small Orchestra, first introductory measures 1 to 4

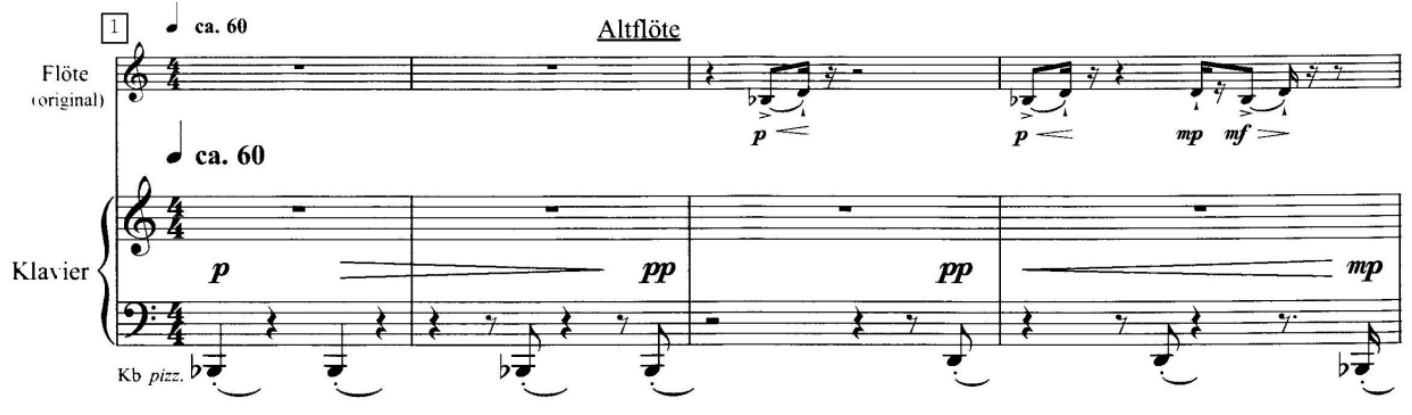

Example 45: Second introduction, measures 104 to 108

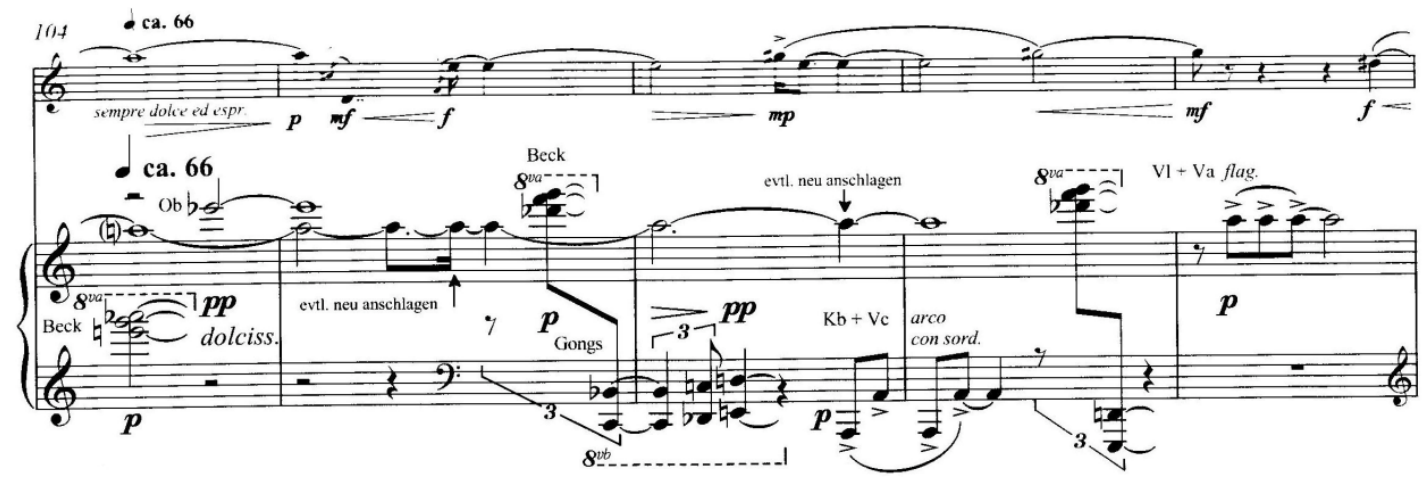

Example 46: Third introduction, measures 172 to 175 and Cadenza

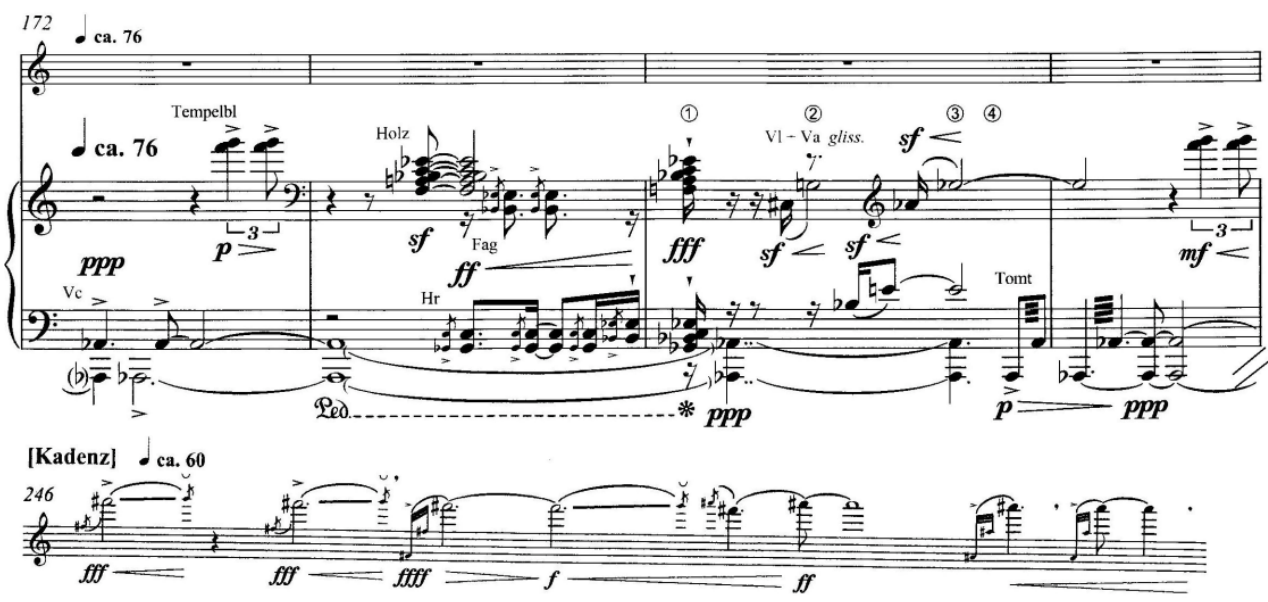


The compositional technique of simplifying the structure of harmony. The sound used in this piece is also represented by various expressions of distinctive advanced trills, various glissandi, and melismas, and it includes a simple dance rhythm with East Asian influences.

In this concerto, the flute and the alto flute are alternated, speaking in a musical language that expresses various emotions or states of consciousness by changing the tone. Yun also wrote that he "carefully wrote this concerto to avoid damaging the beautiful flute sound." 109 Accordingly, the flute in the piece is very delicately expressed, while the orchestra utilizes a wide array of percussive instruments to provide a colorful background for the solo in this piece. This type of texture is typical of East Asian music.

The following is the orchestration that appears in Yun's Flute Concerto. Many percussion instruments that play diverse East Asian sound roles can be seen in this piece:

Instrument Organization of Concerto for Flute and Small Orchestra

* Solo - Flute / Alto Flute

* 1 Flute: the flute tries to sound like a Korean flute, daegeum

* 2 Oboe: follows the method and tone of the flute

* 2 Clarinet, 2 bassoon, 2 horn

* Violin, viola, cello, double bass

${ }^{109}$ Jearyeong Na, “A Study of Isang Yun's selected flute pieces” (DMA dissertation, Seoul National University, 2015), 56. 
* 5 Temple Blocks: unlike a long box-shaped wooden block, it is shaped like a shell, there are five different sized blocks, and is hollowed out to make it resonant: it gives a strong and dry feeling with almost no loud sound, and is suitable for expressing a clear rhythm

* 5 Tomtoms: this is a membranophone drum: the name was derived from that tone, and it is said to have originated in the north of China

* 3 Gongs: discs made of bronze or brass: in Korea, these instruments are called Jing, but the resonance is long and the reverberation is strong (Yun uses this instrument to create a passionate and enthusiastic atmosphere)

* Snare Drum: the snare drum is a percussion instrument introduced into the orchestra for military marches

*Vibraphone: a percussion instrument developed in the United States in the early 20th century. It is a percussion instrument often used to produce sound effects without being used as a solo instrument (like a marimba) because the quality of sound is special.

*3 Cymbals

*2 Triangles

*2 Sleigh Bells

* Hyoshigi: a type of wooden bat that is a percussion instrument first used in Japanese music

In this work, percussion instruments give the Western audience an impressionistic feeling of exotic, Oriental, and delicate feelings. Yun also uses percussion instruments for violent and impulsive emanations, as well as to symbolize inflammatory screaming. 


\section{Analysis of Quartet for Flutes}

The Quartet for flutes, written in 1986, is a work for four flutes: it premiered during the 36th Berlin Festival, with Dagmar Becker, Renate Greiss-Armin, Gaby van Riet-Pas, and Roswitha Stage performing the work at the Berlin Musical Instrument Museum. This quartet was created to warn the listener of the political and social issues occurring at the time of its creation: it is from Yun's third creative period, when he was prominently concerned with such issues.

After around 1975, which was a period when Yun continued to develop his main sound technique into a more understandable concept, he regularly added political or human themes to his compositions. ${ }^{110}$ In the first part of the work, there are descriptions and instructions for the characteristic compositional techniques of this piece: "Innerhalb der Phrasierungen soll möglichst nicht geatmet werden" (As much as is possible do not breathe within the phrases) and "Alle langanhaltenden Tone Möglichst intensive halten" (Keep all sustained notes as intensive as possible). 111

The main tone is treated carefully in the musical core of Yun's work. Besides the instructions, "notes that transcend octaves in legato should accent at each note", performance instructions for each instrument take into account the relationship between the whole of the music and each part of the verse: "We recommend that you keep your space between each other to make space for each sound." 112 In this work, Yun tries to make the most of the flute's tone and rhythm, using piccolo, flute, alto flute, and bass flute with a slightly different tone as well. He is attempting to change the tone of the music continuously by playing various sounds, and aims to express dynamic sound movements through playing techniques such as glissandi, trills, ornaments, and

\footnotetext{
${ }^{110}$ Sung-man Choi and Eunmi Hong, Isang Yun's history of music life (Seoul: Hangil-sa, 1994), 44.

${ }^{111}$ Isang Yun, Quartet for Flutes (London: Boosey \& Hawkes, 1986), 1.

${ }^{112}$ Yun, Quartet for Flutes (London: Boosey \& Hawkes, 1986), 1.
} 
tremolos. ${ }^{113} \mathrm{He}$ is also incorporating his musical background, including Taoism and traditional Korean musical features. The composition of this piece can be divided into four sections, through the arrangement of the instruments, the tone, the character of the movement, and the beat changes.

The first section, as shown as Example 47, is played in slow and dark tones, using two alto flutes and two base flutes as the beginning measures 1 to 44 . The second section is between measures 45-104, beginning as in Example 48 and brightly contrasting with the first section. The third section is between measures 105-156, beginning in Example 49. It is played with two flutes and two piccolos, and symbolizes the moment of resistance where society stands up with frustration in a furious, shouting expression. The fourth and final sections, seen in Example 50, moves through measures 157-192 and uses four instruments: the piccolo, the flute, the alto flute, and the bass flute.

Example 47: Flute Quartet, first introductory measures 1 to 3

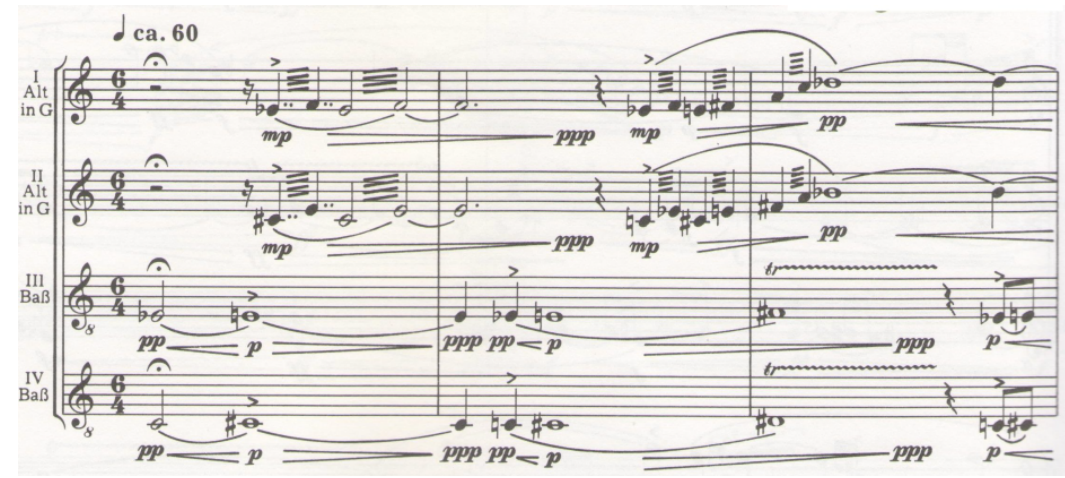

${ }^{113}$ Sung-man Choi and Eunmi Hong, Isang Yun's history of music life (Seoul: Hangil-sa, 1994), 501-510. 
Example 48: Flute Quartet, second introductory measure 45

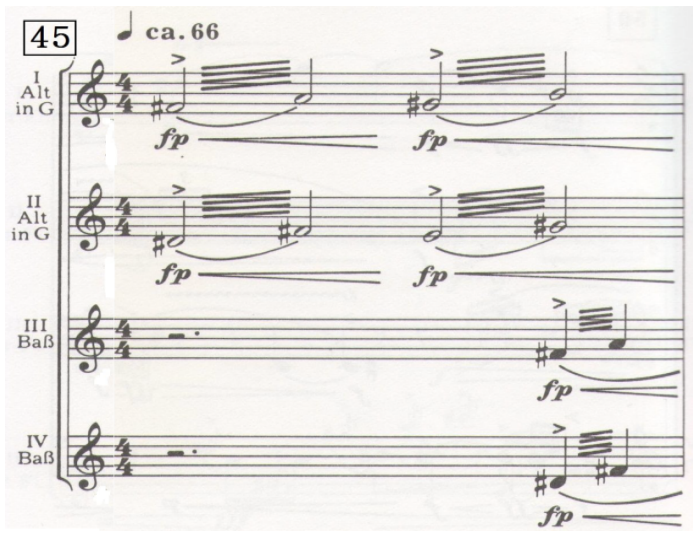

Example 49: Flute Quartet, third introductory measures 105 and 106

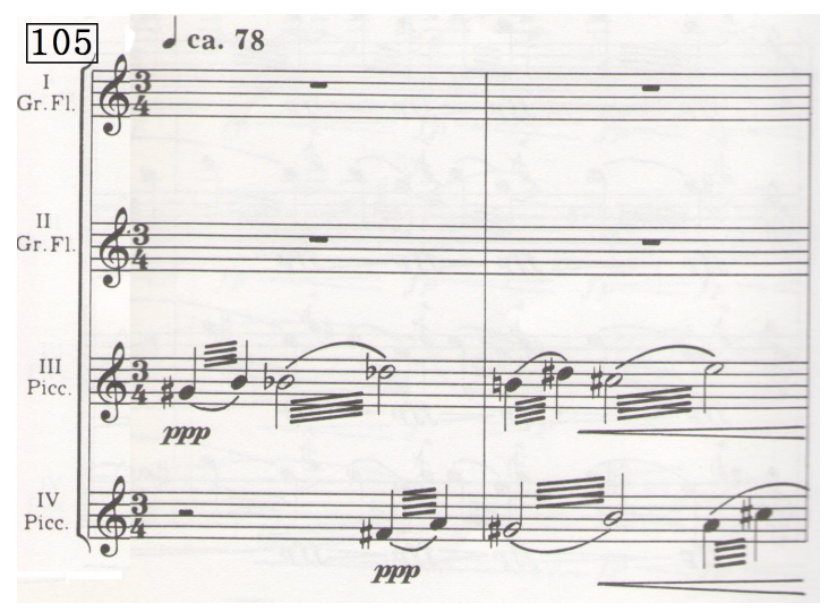

Example 50: Flute Quartet, fourth introductory measures 157 to159

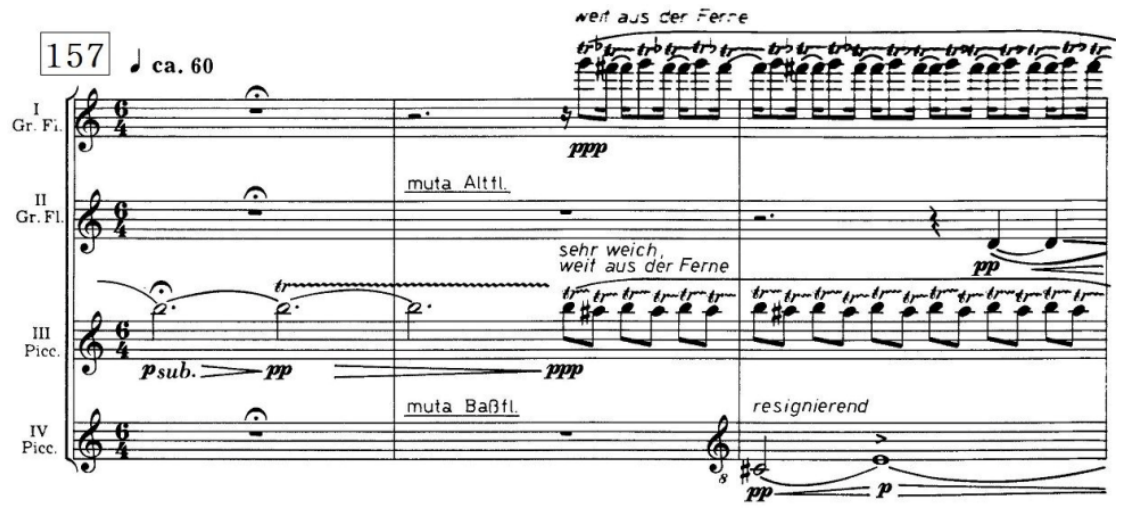


Traditional Korean music and playing techniques are expressed throughout this piece, often through the use of extended flute techniques. The progression of the continuous sounds is expressed by the glissandi and the trills and the wide intervals, which also recalls Korean traditional music. These methods are reminiscent of the Korean melodies used in folk music, such as Jeongakgak, Sinawi and Sanjo, all of which forms of Korean classical music. 


\section{Chapter 6}

\section{Conclusion}

Isang Yun was a twentieth-century composer who incorporated East Asian philosophical, musical, and artistic ideas with Western music. He brought new sounds and his own unique musical language to Western music: East Asian thought and Yun's musical influences from authentic Korean music were fresh attempts at sound creation, different from the avant-garde Western composers of the 1960s and 1970s. "Stillness in motion" and other Taoist philosophies became a staple of Yun's ideological background, and were expressed through various ornaments, types of vibrato, glissandi, and exaggerated dynamics. Today, the Western world craves new and lively sound.

The source of this fresh sound originates from Yun's attachment to East Asian music, such as Buddhist music and the traditional Korean music that he had frequently encountered growing up. This musical experience and deep understanding of and interest in Korean traditional music provided a foundation his work. He composed many flute works, aiming to imitate the acoustic aspects of the Korean traditional wind instrument.

Through the lenses of philosophical precepts, this paper has studied the life of composer Isang Yun and his works for flute, his explorations Taoist ideology, the concept of Yin and Yang, stillness in motion, and finally his humanist spirit. It has also examined the East Asian roots in Yun's music.

With these concepts in mind, an exploration was undertaken of the main tone technique, main sound technique, tone complex, playing around, and other Korean musical techniques used 
by Yun to produce East Asian sounds. Yun's work Sori for solo flute was composed during a composition period when Yun sought to emphasize the main sound by using the main tone technique.

Traditional Korean instruments were examined, along with the nonghyun method, chuseong, junsung and yosung. Yun combined Western musical elements such as ornaments, trills, tremolos, glissandi, various types of vibrato, flutter tonguing, and pitch bending with the aforementioned traditional Korean methods, particularly the minor 2nd, minor 3rd, perfect 4th, perfect 5th, and other intervals that characterize folk music. The use of the decoration sound is conspicuous in Yun's work, as is the pitch relation that is specific to Korean music.

In addition to Sori, this paper explored four pieces of Yun's music for flute, including his Etudes for flute solo, which focuses on the sound of the Korean flute, and Garak, which showcases the vitality of Isang Yun's process: changing the single movement, incorporating East Asian elements, employing the main tone technique, and his emphasis on expressing of Korean emotion by using various decoration methods such as trill, glissando, tremolo, etc. The use of main tone technique and Yun's goal of including more East Asian elements through the use of percussion instruments can all be seen in his Flute Concerto with Small Orchestra. This paper also sought to understand the methods and melodies of traditional Korean music that Yun pursued, as well as his other artistic developments: for instance, in his Quartet for flutes, human subjects were added to the compositional elements. Using four flutes, piccolo, flute, alto flute, and bass flute, this paper explored how a player may change the tone of the music by producing different sounds; research was also presented on dynamic sound movements through various playing techniques, Taoist thought, and traditional Korean musical features. 
Yun's techniques are means of expression: when using these methods in various forms, the player must understand and express subtle differences in the expression of each technique. In addition, these five pieces incorporate both distinctive East Asian philosophy and composition techniques, including Taoism, Yin and Yang, stillness in motion, and Humanism, and Yun's personal techniques, such as the main tone technique, tone complex, sound-color composition and playing around, and Korean traditional musical elements. This research examined the ways in which Yun combined Korean elements and East Asian philosophy with Western forms in his work and how he developed his own unique compositional techniques.

In recent history, many Korean musicians have learned to recognize the different influences present in the music being composed and performed and are able to differentiate between inspirations derived from Korean musical traditions and Western music practices. Isang Yun's work stands out in its ability to interact with global trends while protecting the identity of Korea. It is the goal of this study that students and professional musicians will find this resource useful when studying and performing the works of Isang Yun. Furthermore, additional research and study on the various inspirations behind Isang Yun's works would be a valuable contribution to the existing literature in the field and would serve to promote his works. 


\section{Bibliography}

Beom Seo Han, ed. A Study of Korean Traditional Folk Music. Seoul: TaeRim Sa, 2009.

Choi, Ji Sun. "The Merging of Korean Traditional Music and Western Instrumentation as Exemplified in Four Chamber Works for Piano Composed by Isang Yun.” DMA diss., University of Miami, 2007.

Choi, Sung Man and Eunmi Hong, ed. Isang Yun's History of Music Life. Seoul: Hangilsa, 1994.

Dunbar, Brian. “A Performance Guide to Etüden für Flöte(n) solo by Isang Yun.” DMA diss., Louisiana State University, 2016.

Hauser, Laura. “A Performer's Analysis of Isang Yun's Monolog for Bassoon with an Emphasis on the Role of Traditional Korean Influences." DMA diss., Louisiana State University, 2009.

Hong, Eunmi. “Isang Yun, His Life and His Music.” Monthly Keum Ho Magazine 14 (1995): 24.

Hur, Dae-Sik. "A Combination of Asian Language with Foundations of Western Music: An Analysis of Isang Yun's Salomo for Flute solo or Alto Flute Solo." DMA diss., University of North Texas, 2005.

Jang, Seon Hee. "Interpretation of Extended Techniques in Unaccompanied Flute Works by East-Asian Composers: Isang Yun, Toru Takemitsu, and Kazuo Fukushima.” DMA diss., California State University Long Beach, 2010.

Jun, Eun Jung. “A Full Realization of Isang Yun's Tuyaux Sonores' and Its Analysis Based on Daoism." DMA diss., California State University Long Beach, 2017.

Jung, Joon Il. ed. Introduction to Taoism. Seoul: Seok Chang Sa, 2001.

Jung, Kang Seok. "An Analysis of Concerto for Woodwinds by Isagn Yun." MM thesis, ChangWon University, 2004.

Jung, Kyung Dae, ed. Yin and Yang. Seoul: Seong Bo Sa, 2004.

Kang, Soo Jung. "A Study of Etudes for Flute Solo by Isang Yun." MM thesis, Catholic University, 2005.

Kim, Dae Wook. "The Integration of Western Techniques with East Asian Philosophies in Isang Yun's Quartet Für Horn, Trompete, Pasaune und Klavier." DMA diss., University of North Texa, 2013. 
Kim, Hee Yeon (Julia). "Isang Yun's Duo for Viola and Piano and Korean Traditional Music." DMA diss., Florida State University, 2014.

Kim, Joo Won. "The Development of Contemporary Korean Music with Emphasis on Works of Isang Yun.” DMA diss., The Ohio State University, 2011.

Kim, Ju Hee. "Multicultural Influences in the Music of Isang Yun as Represented in His Concerto for Flute and Small Orchestra.” DMA diss., University of Alabama, 2009.

Kim, Seo Kyung. "Integration of Eastern and Western Music: An Analysis of Selected Flute Works by Korea Composer, Isang Yun.” DMA diss., California State University Long Beach, 2003.

Kim, Song Young. "The Concept of 'Unity' In Isang Yun's Königliches Thema für Violine solo.” DMA diss., University of North Texas, 2011.

Kim, Yong Whan, ed. Research on Isang Yun. Seoul: SiGongSa, 2001.

Kim, Yoon Kyung. "Eastern Philosophy on 'Gasa' for Violin and Piano by Isang Yun.” MM theses, Kyeong Won University, 2008.

Kim, Yun Jeong. “Isang Yun's Violin Concerto No. 1 (1981): A Fusion of Eastern and Western Styles, and the Influence of Taoism.” DMA diss., University of Cincinnati, 2013.

Lee, Ear Ryung, ed. Communication with World Famous People. Seoul: Moon Hwa Sang Sa, 2004.

Lee, Jeong Seok. "The Interaction of Korean and Western Practice in Isang Yun's Piri for Oboe Solo and Other Works.” DMA diss., California State University Long Beach, 2011.

Lee, Mi Kyung. "Music and Korea.” Magazine of Korean Arts 22 (2001): 1-10.

Lee, Young Ju. "Isang Yun's Musical World: A guide to Two Songs and the Opera Sim Tjong." DMA diss., Florida State University, 2009.

Moon, Jin Kyung. "Study of Isang Yun's Exemplum in Memoriam Kwangju." DMA diss., University of Georgia, 2017.

Na, Jaer Young. “A Study of Isang Yun's Selected Flute Pieces.” DMA diss., Seoul National University, 2015.

Park, Edward. "The Life and Music of Isang Yun.” DMA diss., California State University Long Beach, 2014.

Ro, Sophia. “Reading Isang Yun's Concerto No. 3 Beyond Western Notational Norms.” DMA diss., University of North Texas, 2014. 
Sun, Seo Young. "A Study of Traditional Compositional Techniques of Sori for Flute Solo (1988) by Isang Yun.” Master’s thesis, Chang Won University, 2013.

Yun, Isang and Walter-Wolfgang Sparrer, ed. My Way, My Ideal, My Music. Seoul: Hice, 1994. 